\title{
Hole-mediated PhotoRedox Catalysis: Tris(p-substituted)biarylaminium Radical Cations as Tunable, Precomplexing and Potent Photooxidants.
}

Shangze Wu, ${ }^{\dagger}$ Jonas Žurauskas, ${ }^{\dagger+}$ Michał Domański, ${ }^{\dagger+}$ Patrick S. Hitzfeld, ${ }^{\dagger+}$ Valeria Butera, ${ }^{\perp}$ Daniel J. Scott, ${ }^{\dagger}$ Julia Rehbein,${ }^{\dagger}$ Ajeet Kumar, ${ }^{\S}$ Erling Thyrhaug, ${ }^{\S}$ Jürgen Hauer, ${ }^{\S}$ and Joshua P. Barham ${ }^{*}$

*Corresponding Author. E-mail: Joshua-Philip.Barham@chemie.uni-regensburg.de

$\dagger$ Universität Regensburg, Fakültat für Chemie und Pharmazie, 93040 Regensburg, Germany

${ }^{\perp}$ Central European Institute of Technology, CEITEC, Brno, 61200 Czech Republic

§Technische Universität München, Fakültat für Chemie, 85748 Munich, Germany

\begin{abstract}
Electrochemically-mediated Photoredox Catalysis emerged as a powerful synthetic technique in recent years, overcoming fundamental limitations of electrochemistry and photoredox catalysis in the single electron transfer activation of small organic molecules. However, the mechanism of how photoexcited radical ion species with ultrashort (picosecond-order) lifetimes could ever undergo productive photochemistry has eluded synthetic chemists. We report tri(para-substituted)biarylamines as a tunable class of electroactivated photocatalysts that become superoxidants in their photoexcited states, even able to oxidize molecules (such as dichlorobenzene and trifluorotoluene) beyond the solvent window limits of cyclic voltammetry. Furthermore, we demonstrate that precomplexation not only permits the excited state photochemistry of tris(para-substituted)biarylaminium cations, but enables and rationalizes the surprising photochemistry of their higher-order doublet $\left(\mathrm{D}_{n}\right)$ excited states.
\end{abstract}


Introduction Synthetic Organic Electrochemistry (SOE) (1-5) and visible light PhotoRedox Catalysis (PRC), (6-12) which offer entries to single electron transfer (SET) chemistry and radical intermediates under mild conditions, have risen to the fore of contemporary organic synthesis. A key factor underpinning the success of PRC is the host of available photocatalyst structures with well-characterized photophysical and redox data, allowing chemists to match a given excited state to a desired process. Although PRC exhibits a selectivity benefit in transferring the energy of visible light photons to a colored transition metal-based or organic dye photocatalyst, its scope of applications are redox potential-limited by the energy of single photons (ca. 1.8-3.1 eV). Multiple-photon-accumulating strategies such as consecutive photoelectron transfer (conPET) (13-17) and triplet-triplet annihilation upconversion (TTA-UC), (18-20) have represented an elegant means to achieve powerful SET reductions, but their use in oxidations has so far been elusive. However, these techniques place limiting requirements on reactions, such as the requirement in conPET for both ground and radical ion states to be visible-light active. Furthermore, net-oxidative/reductive PRC processes employ excess of a sacrificial oxidant/reductant which is necessary for photocatalyst turnover, but which may (or whose by-products may) i) interfere with the desired downstream chemistry and ii) may require separation from the desired products. The conPET strategy likewise suffers from this requirement. In comparison to PRC processes, SOE can employ uncapped potentials to chemical redox reactions at the turn of a dial. However, electrode surfaces typically (21-22) cannot discriminate between organic molecules aside from their innate order of thermodynamic redox potentials. Moreover, low electrical conductivity in organic solvents typically require applied potentials to be higher than the redox potential of the target substrate. (23) This encourages deleterious higher order or solvent redox processes especially if target SET processes lie near the solvent electroactive window ( +3 to $-3 \mathrm{~V}$ for typical electrolyte-containing solvents). (23-25) In addition, mechanistic characterization of the heterogeneous "electrocatalysis" step (referring to heterogeneous SET at the electrode surface) (26) has remained a key challenge in SOE. Screening of electrode materials is often inevitable, despite best efforts to characterize materials by overpotential, electrical resistivity, surface area, stability and cost. (27-28) As a result of these limitations, in recent years synthetic photoelectochemistry is emerging as a state-of-the-art in SET-mediated chemistry. (29-33) Different categories for the merger of photochemistry and electrochemistry have been reported, including interfacial photoelectrochemistry (iPEC) involving photoelectrodes (34-37) and 
decoupled photoelectrochemistry (APEC) where photo- and electrochemical steps serve separate roles in the reaction mechanism. (38-39)

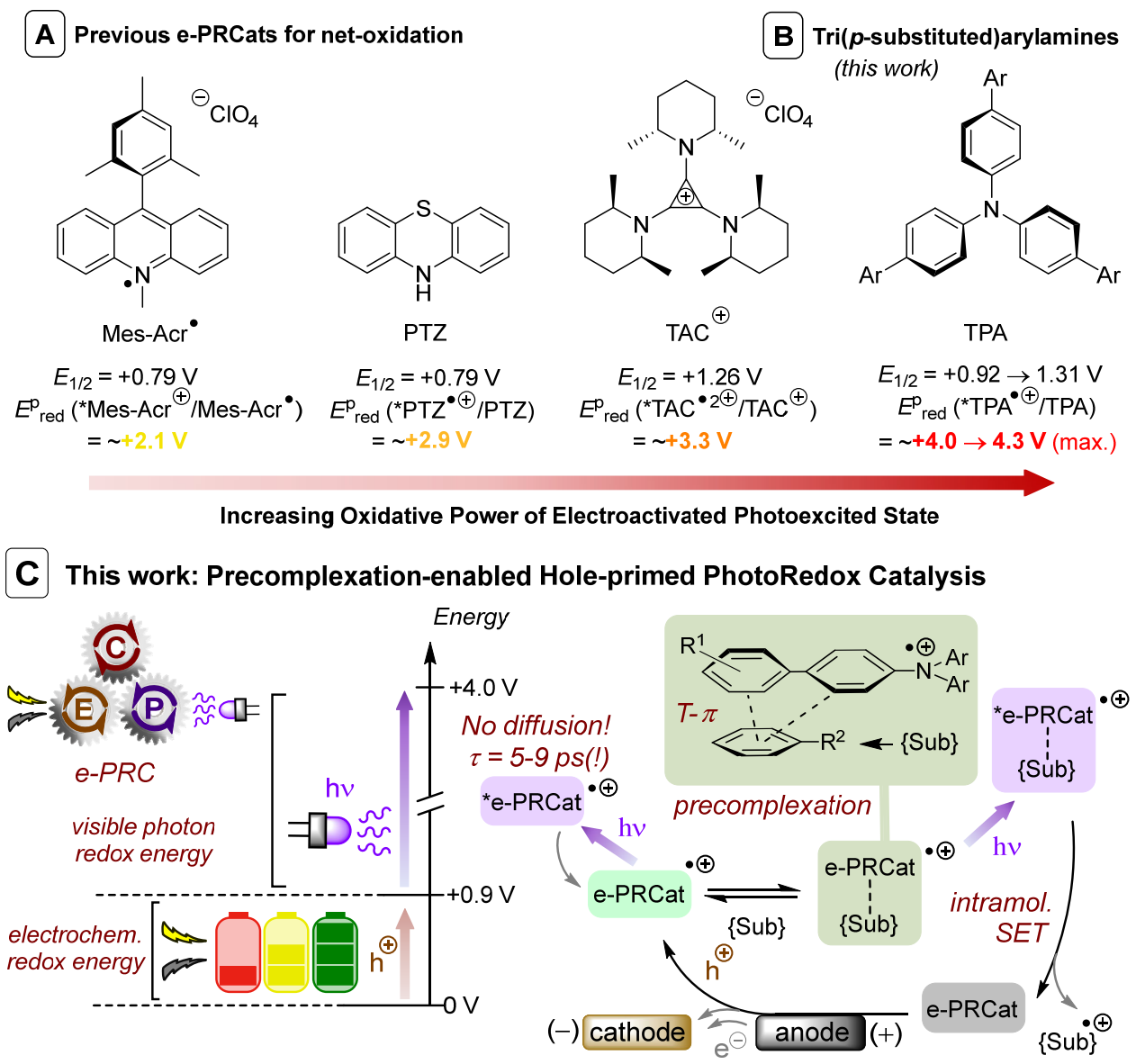

Figure 1: A. Electroactivated Photoredox Catalysts employed in net-oxidative synthetic processes. B. Triarylamines as e-PRC catalysts. C. This work.

A third category involves an intimate and synergistic relationship of photo- and electrochemical steps within the same catalytic cycle. (40-51) A variety of nomenclature has been coined in the literature for this sub-category of PEC, such as: "electrophotocatalysis" $(45-47,51)$ "photoelectrocatalysis" $(46,50)$ and "electron-primed photoredox catalysis" (51). We coined the general nomenclature "electrochemically-mediated PhotoRedox Catalysis (e-PRC)" as a blanket term to cover both net-oxidative and net-reductive variants (29) and to avoid misunderstanding with iPEC. e-PRC leverages the unique benefits of both parent technologies PRC and SOE in order to i) compile potential and photon energies to achieve photocatalyst excited-state potentials beyond those normally accessible via visible light photons alone $(44-46,51)$ and to ii) obviate the need for sacrificial oxidants/reductants. $(48,50)$ Pioneering reports on e-PRC realized these benefits in a number of net-reductive/net-oxidative transformations. (44-51) In the net-oxidative direction, previous 
examples of electroactivated PhotoRedox Catalysts (e-PRCats) include i) 9-mesityl-10-methylacridinium dye, (44) ii) phenothiazine (40) and iii) an exotic trisaminocyclopropenium cation, (45) which have accomplished SET oxidations from alkyl-substituted arenes up to challenging chloroarenes. Elsewhere, tri( $p$-substituted)arylamines, discovered by Walter and co-workers (52) are renowned for their photophysical properties as hole-transport materials in OLEDs and in photovoltaics, (53-54) as oxidative mediators in SOE (55-59) and as oxidants in radical chain reactions. (60-61) They exhibit fully reversible $1 \mathrm{e}^{-}$ oxidations by cyclic voltammetry. Generally colorless in their neutral state, their oxidized tris(para-substituted)aminium radical cation forms are intensely colored. While the commercial tris(4-bromophenyl)aminium radical cation presents issues and non-innocence as an oxidant in synthesis, (62-64) better behaved radical cations could derive from tri(para-substituted)biarylamines (TPAs) that are in turn easily be prepared in a single/few steps from Pd-catalyzed cross-coupling reactions of tri-p-bromophenylamine with appropriate partners or after appropriate activation. Barham et al. reported the use of tris(para-substituted)arylaminium radical cations bearing $p$-Me or $p$-Ph substituents that exhibited good stability in solution and excellent stability as isolated solids, that mediated highly selective $\mathrm{N}-\mathrm{CH}_{3}$ oxidative functionalization reactions. (65) Given their favorable properties and facile synthetic accessibility, we foresaw TPAs as a suitable class of customizable e-PRC catalyst that would open new avenues to customize redox and photophysical parameters of e-PRCats; an important concept which has not yet been disclosed. Although moderate oxidants in their tris(para-substituted)biarylaminium $\left(\mathrm{TPA}^{+}\right)$state, subsequent photooxidation would provide formidable oxidation potentials. Moreover, the excellent stability of isolated TPA $\cdot^{+} \mathrm{s}$ could be leveraged in i) probing the reaction mechanisms of their e-PRC reactions and ii) their photophysical characterization. Herein, we disclose TPAs as powerful and effective e-PRCats that engage unactivated or electron-poor aromatic systems $\left(E^{\mathrm{p}} \mathrm{ox}=+2.1 \mathrm{~V}\right.$ to $\left.>3.0 \mathrm{~V}\right)$ in SET oxidation. Of key importance is the discovery of precomplexation in the ground state, which i) circumvents ultrashort lifetimes of excited states, ii) allows engagement of higher order excited states and iii) enables contra-thermodynamic redox selectivity. Photoexcited triarylaminium radical cations are demonstrated as novel superoxidants in organic synthesis (Figure 1). 
Synthetic Results We began by screening different TPA e-PRCats (Generation 1, Figure 2) with different half-wave oxidation potentials in the Nicewicz model reaction; (66) the oxidative C-H amination of mesitylene $\left(E^{\mathrm{p}_{\mathrm{ox}}}=+2.1 \mathrm{~V}\right.$ vs. SCE) (66) with pyrazole (Table 1). A carbon foam anodic working electrode (WE) and Pt cathodic counter electrode (CE) were employed in a H-cell divided by a porous frit, whose anodic compartment was placed atop a water-cooled block atop a $400 \mathrm{~nm}$ LED. Acetic acid was employed as a proton source for the cathodic half-reaction. TPA catalysts were typically poorly soluble in $\mathrm{MeCN}$ containing $0.1 \mathrm{M}{ }^{\mathrm{n}} \mathrm{Bu}_{4} \mathrm{~N} \cdot \mathrm{PF} 6$. After setting an anodic constant potential of $\mathrm{U}_{\text {cell }}=+1.4 \mathrm{~V}$ (Figure 3), solid particles gradually disappeared and color developed in the anodic compartments for each TPA e-PRCat, consistent with the expected formation of their $\mathrm{TPA}^{+}{ }^{+}$s. Gratifyingly, irradiation under the specified conditions afforded C-H activation product 3aa. No product was observed in the absence of light and only traces in the absence of potential (4\%) or TPA e-PRCat (2\%), confirming the operation of e-PRC. Generally, the yield of 3aa increased with increasing oxidation half-wave potentials $\left(E_{1 / 2}\right)$ of the TPA (Figure 2 and Table 1, entries 1-3), suggesting that the TPA.+'s excited state potential is more relevant to success than the steady-state concentration of electrogenerated radical cation.
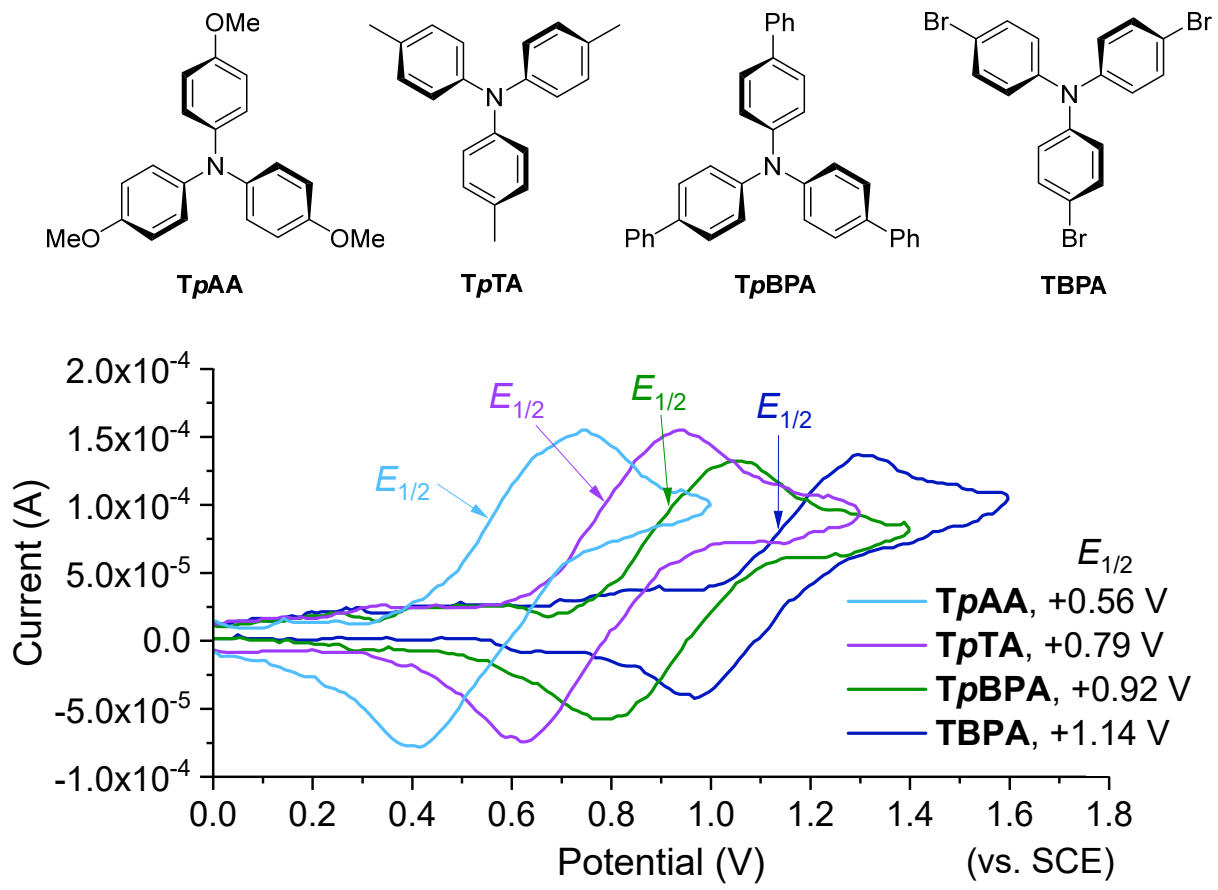

Figure 2. Generation 1 TPA e-PRCats (top). Cyclic voltammograms of Gen. 1 e-PRCats (bottom). 
Table 1. Optimization of e-PRC C-H heteroamination using first generation TPAs.

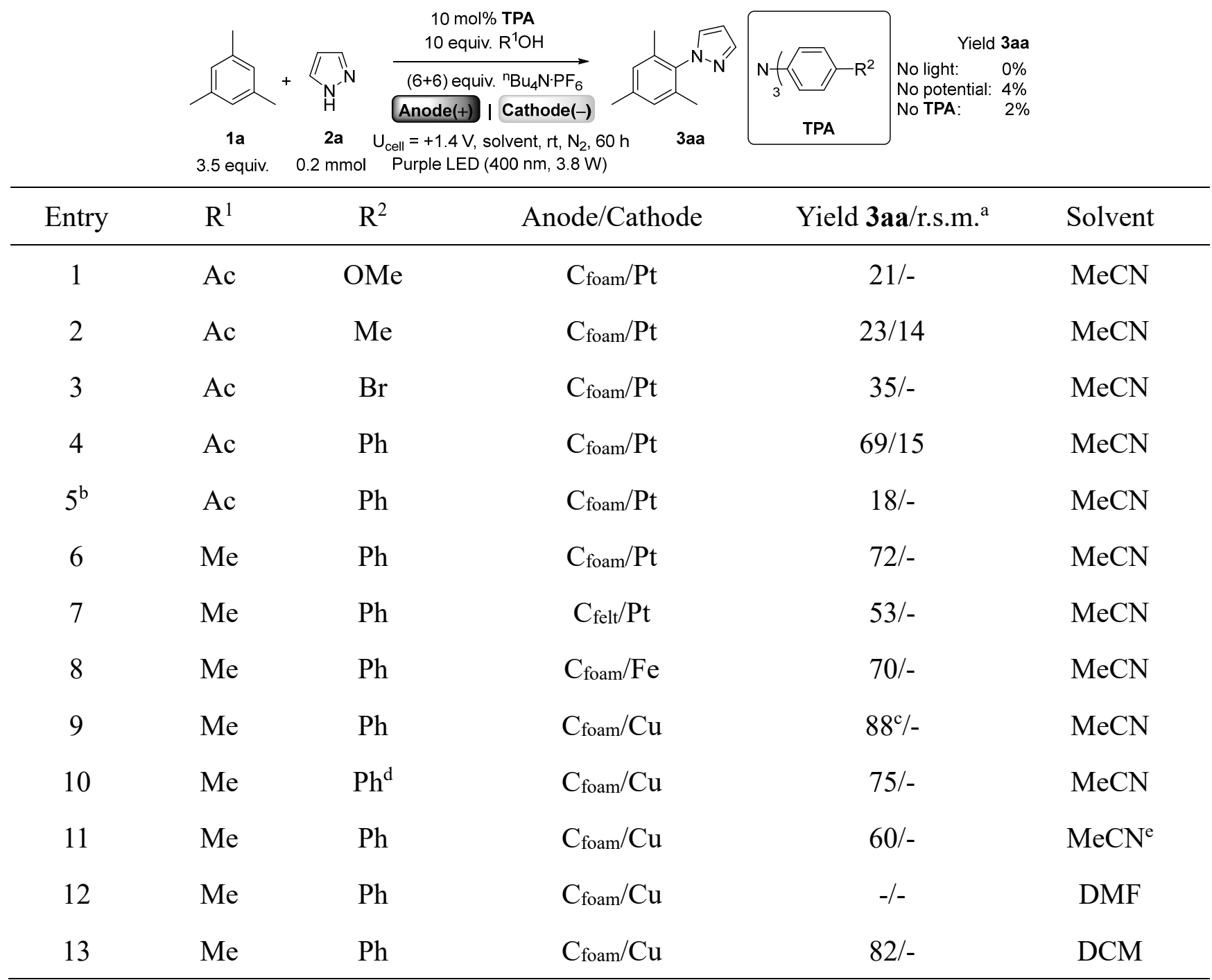

r.s.m., returned starting material. ${ }^{a}$ Yields determined by ${ }^{1} \mathrm{H}$ NMR using dibromomethane as an internal standard. ${ }^{\mathrm{b}} 0.35 \mathrm{~W} 400 \mathrm{~nm}$ LED. ${ }^{\mathrm{c}}$ Average of two replicates. ${ }^{\mathrm{d}} 5 \mathrm{~mol} \%$ TPA was used. ${ }^{\mathrm{e}} \mathrm{LiClO}_{4}$ used as electrolyte.

Interestingly, tri([1,1'-biphenyl]-4-yl)amine (TpBPA) afforded a notably higher yield of 3aa than the commercial tris(4-bromophenyl)amine (entry 4) despite having an appreciably lower $E_{1 / 2}$. Comparisons of the UV-visible spectra of $\mathrm{TPA}^{+}$revealed a plausible explanation; that TpBPA benefitted from the strongest absorption at $400 \mathrm{~nm}$. Decreasing LED input power by $c a$. 10x decreased the yield (entry 5). Screening of other protic sources revealed $\mathrm{MeOH}$ to be most effective (entry 6). Carbon foam was a superior anodic WE to carbon felt, likely due to its higher surface area (entries 6-7). Gratifyingly, screening of other CE materials revealed copper to be the optimal cathodic CE (entries 8-9). A decreased TpBPA loading (5\%) gave an inferior (but still high) yield (entry 10) and $\mathrm{LiClO}_{4}$ as an electrolyte was inferior (entry 11). While DMF as solvent gave no reaction, we were surprised the reaction performed well in DCM as solvent, despite its lower 
conductivity (entries 12-13). The yield of 3aa tracked well with increasing applied constant potential (Figure 3). For full optimization studies, see the Supplementary Information.
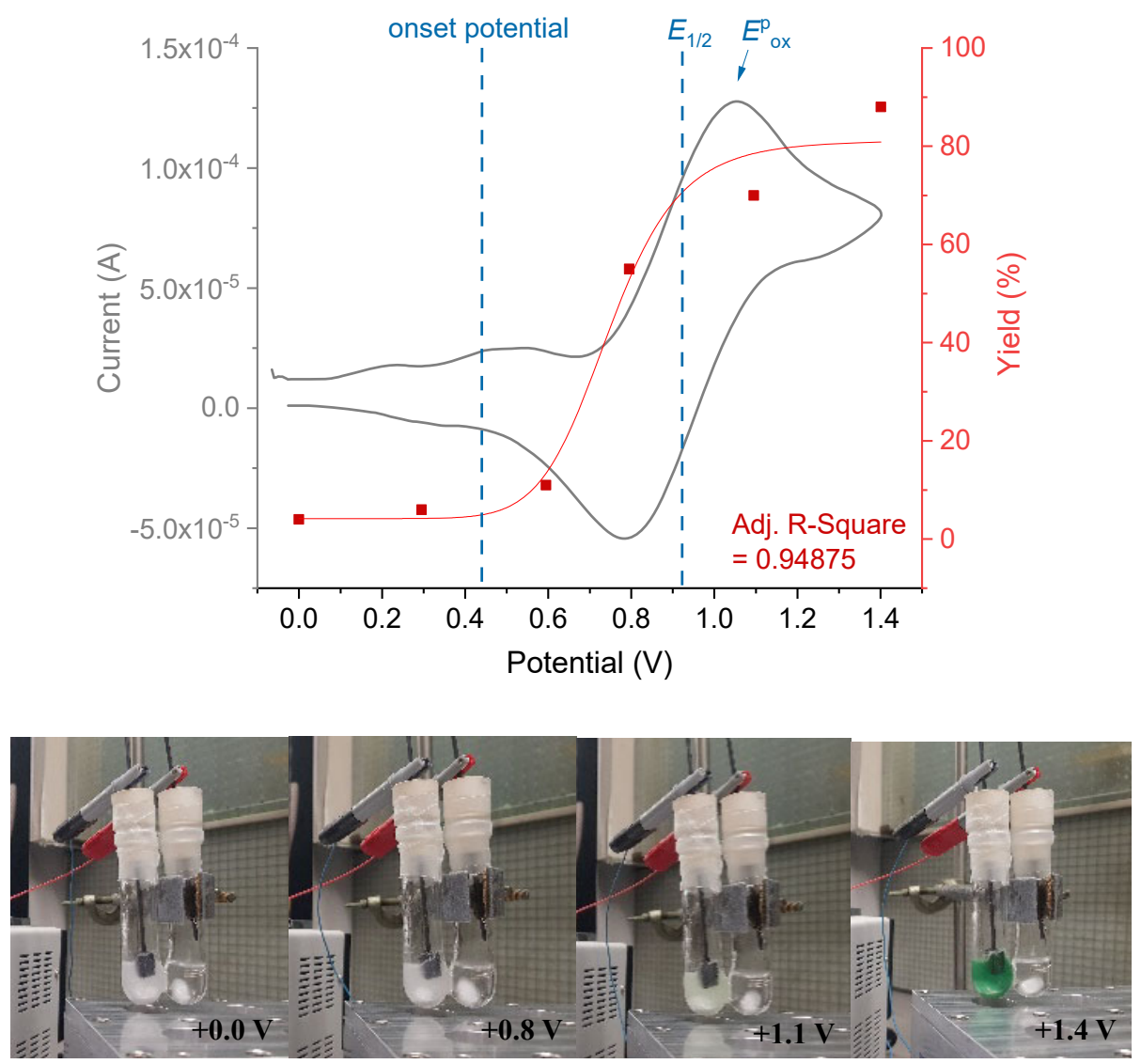

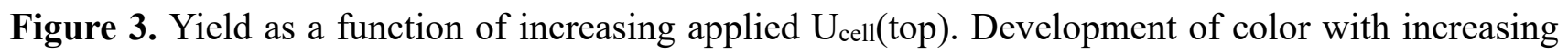
applied $\mathrm{U}_{\text {cell }}($ bottom).

With optimal conditions in hand, the amination of arenes with a variety of pharmaceutically-relevant $N$-heterocycles was explored (Table 2). Halide-bearing and carbonyl (aldehyde, ketone and ester)-bearing pyrazoles, triazole, benzotriazole, and a functionalized derivative of benzimidazole afforded generally good to excellent (50-89\%) yields of aminated mesitylenes 3aa-3aj. We note that benzimidazole derivatives have not been reported as nucleophiles in previous photoelectrochemical arene amination or conPET photocatalytic methods. (37,45,67) 6-Chloro-2-fluoropurine afforded a modest yield of 3ak (32\%), presumably due to its steric hinderance as a nucleophile. Xylenes and toluene were tolerated to afford aminated arenes $\mathbf{3 b b - 3 f b}$ in moderate to excellent (30-88\%) yields. 
Table 2. e-PRC C-H heteroaminations using TpBPA.
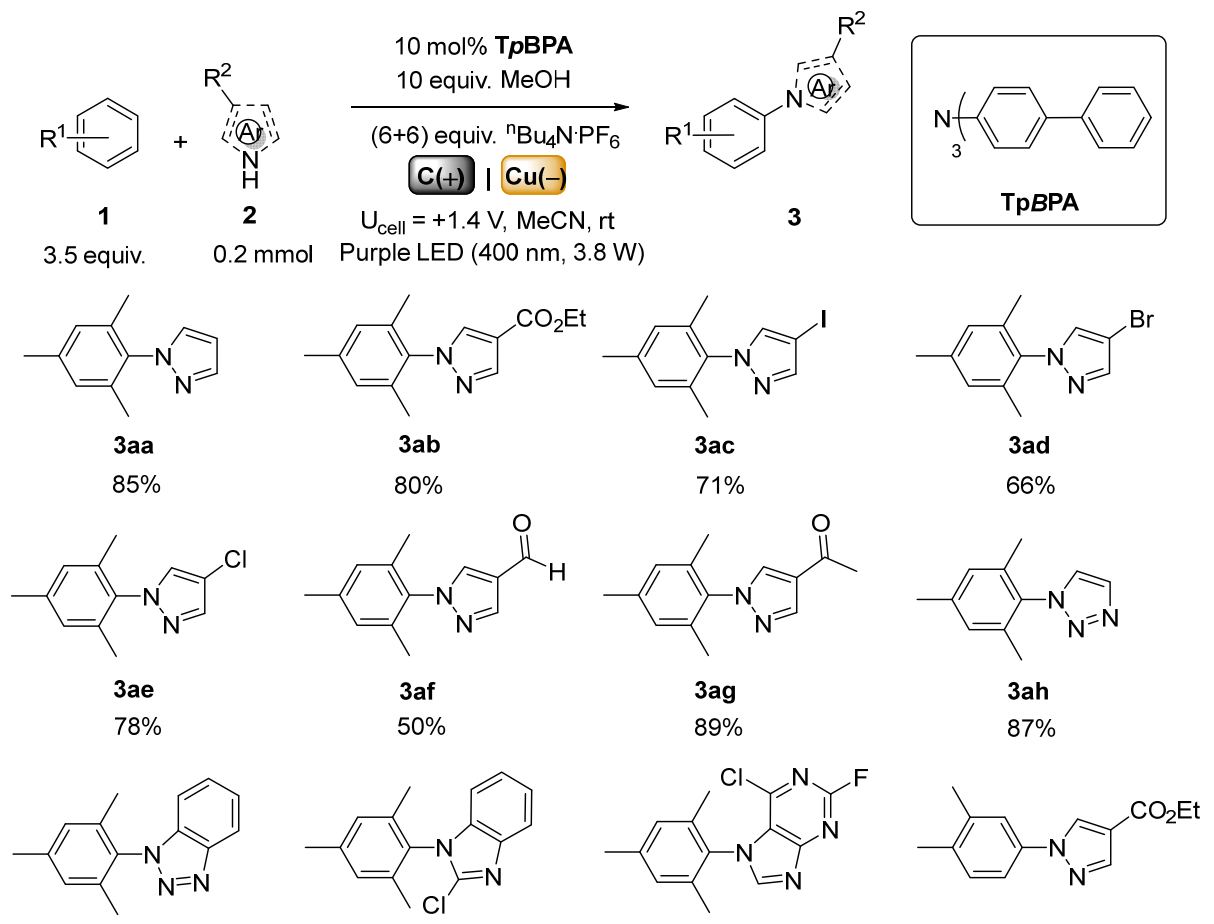

3ai

3aj

$53 \%$

3ak

$32 \%$

$3 \mathbf{b b}$

$62 \%(1 \mathrm{~mL})$
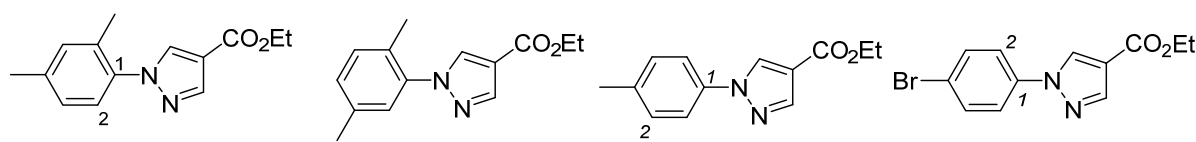

$3 \mathrm{cb}$

$88 \%(1 \mathrm{~mL})$ $10: 1 \mathrm{C}_{1} / \mathrm{C}_{2}$

$3 \mathrm{db}$

$30 \%(1 \mathrm{~mL})$

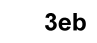

$81 \%(1 \mathrm{~mL})$ $1.7: 1 \mathrm{C}_{1} / \mathrm{C}_{2}$

$30 \%$ (48\% r.s.m., $1 \mathrm{~mL}$ )

$\mathrm{CO}_{2} \mathrm{Et}$

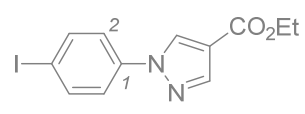

$0 \%(60 \% \text { r.s.m. })^{a}$

Unless otherwise stated, all reactions used 3.5 eq. arene; isolated yields. Yields in parenthesis determined by ${ }^{1} \mathrm{H}$ NMR. ${ }^{\mathrm{a}} \mathrm{A} \mathrm{Pt} \mathrm{CE}$ was used and $\mathrm{AcOH}$.

Interestingly, the product yields of xylenes followed the order meta- > ortho- > para-xylene, despite the $E^{\mathrm{p}}$ ox following the opposite trend. (68) Toluene has an even higher $E^{\mathrm{p}}$ ox than xylenes but reacted to give $81 \%$ of $\mathbf{3 e b}$ (68) Bromobenzene afforded a $30 \%$ yield of $\mathbf{3 f b}$ with notable r.s.m., while iodobenzene gave no reaction at all (60\% r.s.m.). Benzene and $\mathrm{PhCl}$ were unsuccessful, presumably due to their notably higher $E^{\mathrm{p}}$ ox (only a $10 \%$ yield of $\mathbf{3 g b}$ 's combined $\mathrm{C}_{1} / \mathrm{C}_{3}$ isomers was obtained, even when using a large excess of $\mathrm{PhCl}$ and after $72 \mathrm{~h}$ ). Substitution of $\mathrm{Cu}$ for $\mathrm{Pt}$ wire cathode increased the yield to $15 \%$; substitution of $\mathrm{MeOH}$ for $\mathrm{AcOH}$ increased the yield to $35 \%$ (Table 3). Despite exhaustive efforts, we could not improve the conversion/yield beyond this threshold. 


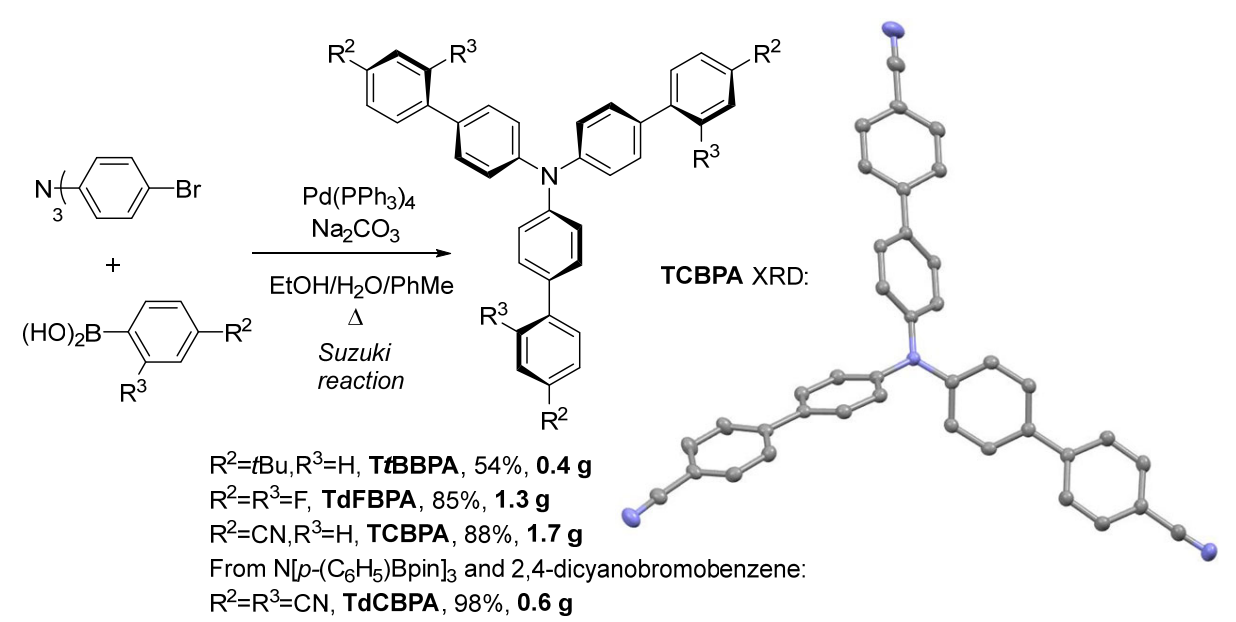

From $\mathrm{N}\left[\mathrm{p}-\left(\mathrm{C}_{6} \mathrm{H}_{5}\right) \text { Bpin }\right]_{3}$ and 2,4-dicyanobromobenzene:

$\mathrm{R}^{2}=\mathrm{R}^{3}=\mathrm{CN}, \mathrm{TdCBPA}, 98 \%, 0.6 \mathrm{~g}$

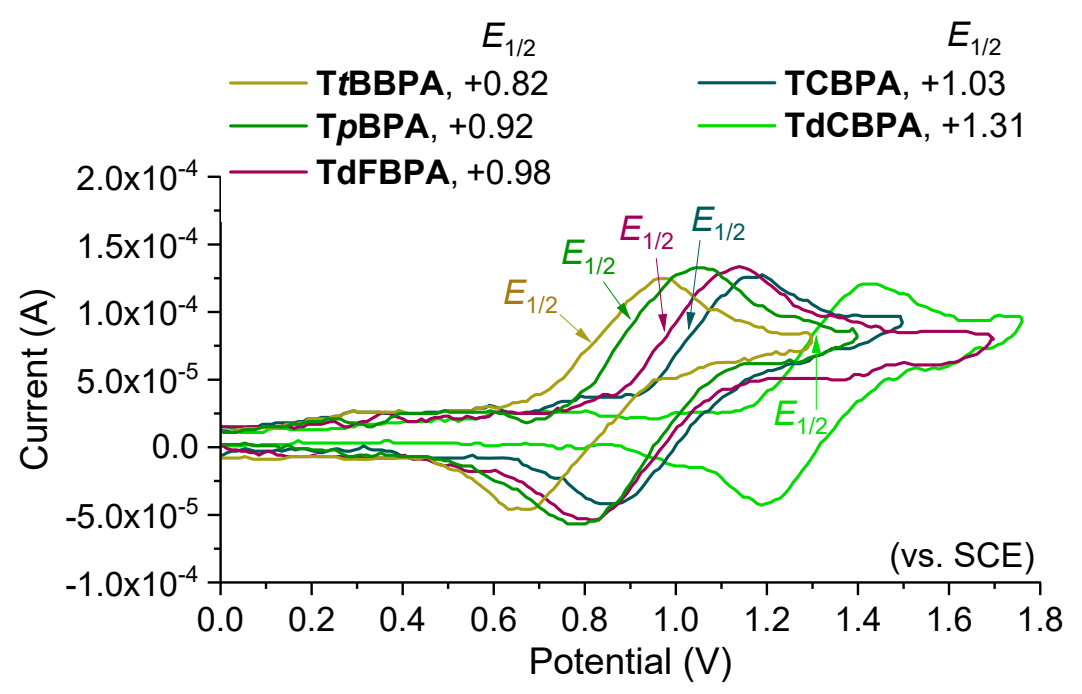

Figure 4. Generation 2 TPA e-PRCats, and the XRD structure of TCPBA. Thermal ellipsoids are set at the $50 \%$ probability level. Hydrogen atoms are omitted for clarity. $\mathrm{C}$ atoms shown in grey, and $\mathrm{N}$ atoms in blue.

Leveraging the facile synthetic customization of TPAs, we synthesized derivatives of TpBPA (Figure 4) with electron-withdrawing groups to bolster their respective TPA.+ excited state potentials (entries 1-4). Of these, we were delighted to find that tris(4'-cyano-[1,1'-biphenyl]-4-yl)amine (TCBPA) increased the yield of $\mathbf{3 g b}$ to $46 \%$ (Table 3). In contrast to TpBPA, the optimal TCBPA catalyst loading was $5 \mathrm{~mol} \%$ (entries 4-8), increasing the yield of $\mathbf{3 g b}$ to $69 \%$ with no detected starting material (entry 6). Notably, the reaction was still quite efficient with only $1.5 \mathrm{~mol} \%$ of TCBPA (entry 8). With these optimal conditions in hand, reactions of $\mathrm{PhCl}$, benzene and even fluorobenzene were enabled, affording 3gb-3ib in modest to good (30-65\%) yields (Table 4). 
Table 3. Optimization of e-PRC C-H heteroamination using Generation 2 TPAs.

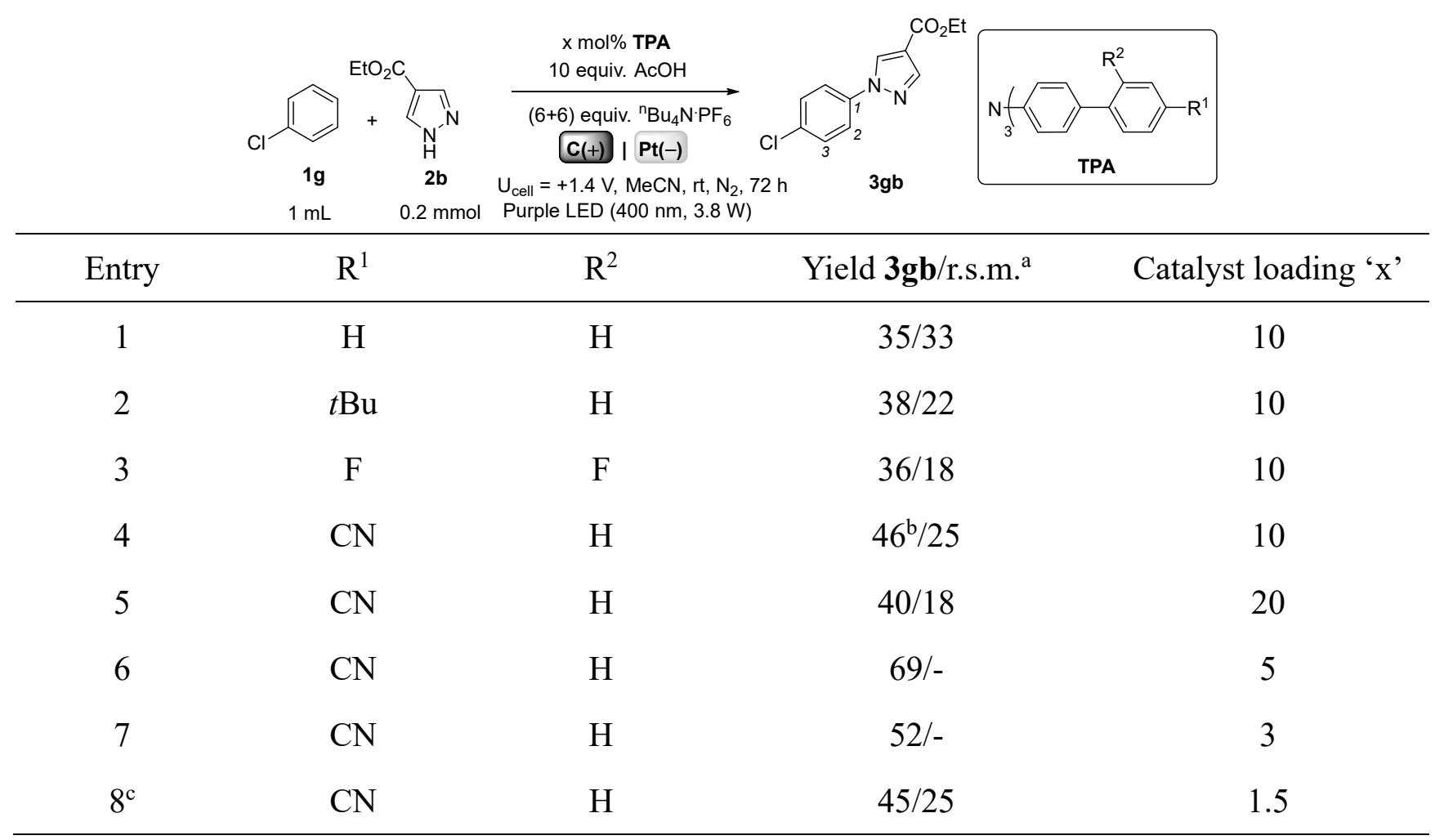

r.s.m., returned starting material. ${ }^{\mathrm{a}}$ Yields determined by ${ }^{1} \mathrm{H}$ NMR using dibromomethane as an internal standard. ${ }^{b}$ Average of two replicates. ${ }^{\mathrm{c} T h e}$ reaction was conducted with $\mathbf{1 g}(1 \mathrm{~mL}), \mathbf{2 b}(0.4 \mathrm{mmol})$, TCPBA $(0.006 \mathrm{mmol})$, $\mathrm{AcOH}(4 \mathrm{mmol}),{ }^{\mathrm{n}} \mathrm{Bu}_{4} \mathrm{~N} \cdot \mathrm{PF}_{6}((1.2+1.2) \mathrm{mmol}), \mathrm{MeCN}(3.5+3.5 \mathrm{~mL})$.

Interestingly, under the same applied constant potential $U_{\text {cell }}$ as in Table 2 and in contrast to the use of TpBPA, here toluene underwent benzylic oxidation instead of amination, while a pyrazole-4-carboxaldehyde (either before or after benzene $\mathrm{C}-\mathrm{H}$ amination) underwent oxidation to its carboxylic acid (Table 4, bottom). Bromobenzene gave a lower yield of $\mathbf{3 f b}$ than that in Table $\mathbf{2}$. The above observations indicate a less oxidizing $\mathrm{TPA}^{*^{+}}$excited state (such as that from $\mathbf{T} p \mathbf{B P A} \mathbf{*}^{+}$) is beneficial for certain substrates and demonstrates the value of tunability presented by this class of e-PRCats. We further probed the limits of arene SET oxidations with TCBPA $^{+}$, by targeting 1,2-dichlorobenzene and trifluorotoluene, and were encouraged to detect products, albeit in low yields, from each when using TCBPA (17\% of $\mathbf{3 j b}$ and 7\%, respectively). Yields did not increase with extended reaction time $(96 \mathrm{~h})$ or higher applied potential $\left(\mathrm{U}_{\text {cell }}=+1.8 \mathrm{~V}\right)$, which suggested that we had reached the oxidizing limit of this photoexcited TPA ${ }^{+}$. 
Table 4. e-PRC C-H heteroamination using TCBPA.

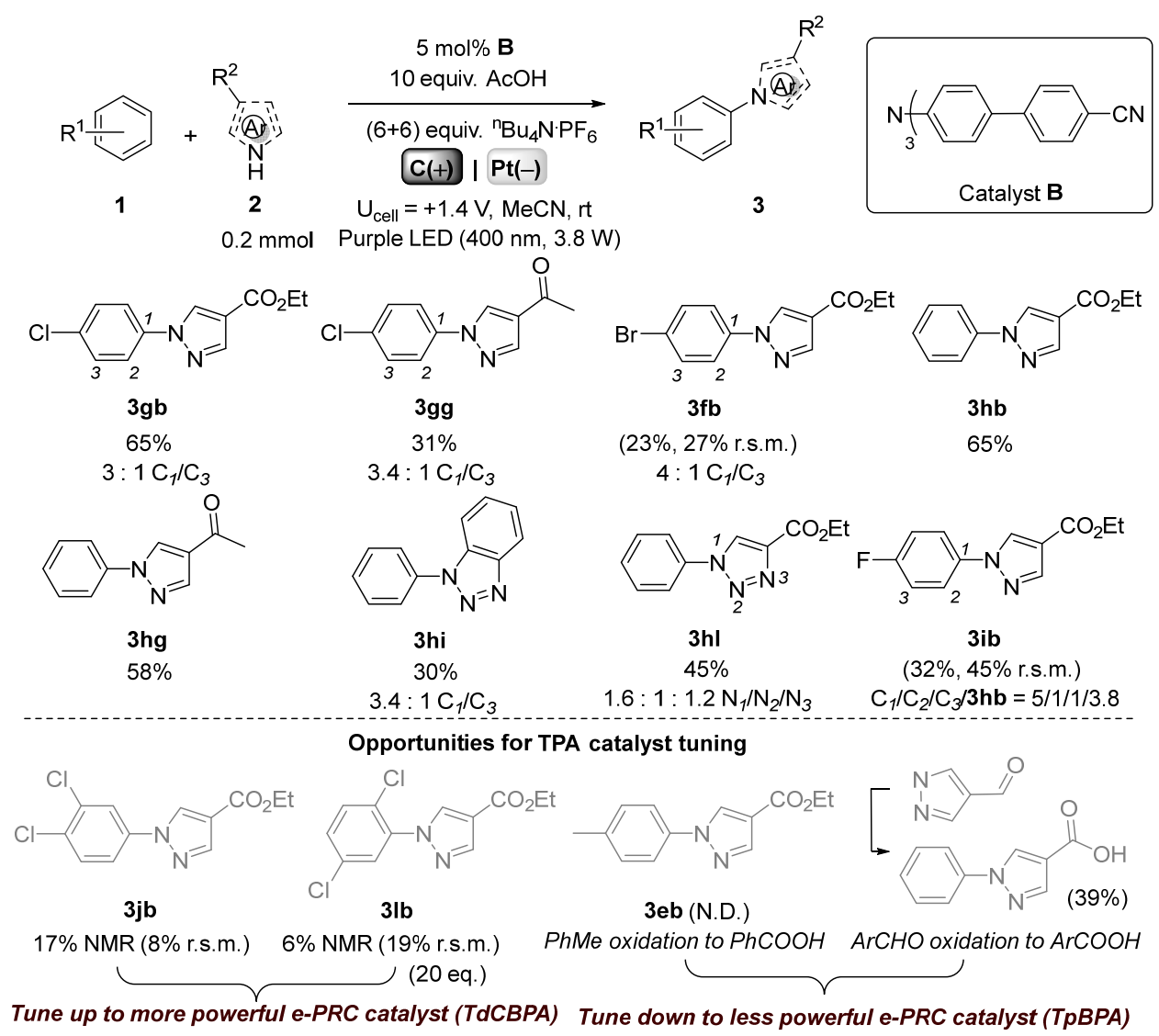

N.D. not determined. Unless otherwise stated, all reactions used $1 \mathrm{~mL}$ arene; isolated yields. Yields in parenthesis determined by ${ }^{1} \mathrm{H}$ NMR.

Gratifyingly, further e-PRCat tuning in the form of the even more electron-deficient tris(2',4'-dicyano-[1,1'-biphenyl]-4-yl)amine (TdCBPA) increased the yield of $\mathbf{3 j b}$ to a much more satisfactory $31 \%$ (Table 5). Although polyfluorinated arenes were activated to afford $\mathbf{3 o b}$ and $\mathbf{3 h b}$ in only modest yields $(\sim 20 \%)$, it should be emphasized that oxidative $\mathrm{S}_{N} A r-t y p e$ activation of such challenging substrates with pyrazoles has not to our knowledge been previously accomplished. In competition with $\mathrm{C}-\mathrm{H}$ activation, $\mathrm{C}-\mathrm{F}$ substitution occurred to give 3ob. $(46,69)$ Interestingly, $\mathrm{C}_{6} \mathrm{H}_{5}$-bearing compound $\mathbf{3 h b}$ was isolated from the reaction of trifluorotoluene, indicating a $\mathrm{S}_{\mathrm{N}} \mathrm{Ar}$ of a $\mathrm{CF}_{3}$ group. While the role of $\mathrm{CF}_{3}$ groups in promoting $\mathrm{S}_{\mathrm{N}} \mathrm{Ar}$ reactions is well-known, to our knowledge no prior examples of a formal $\mathrm{C}\left(\mathrm{sp}^{2}\right)-\mathrm{CF}_{3}$ to $\mathrm{C}\left(\mathrm{sp}^{2}\right)-\mathrm{N}($ Het-Ar) substitution exist. The oxidation potentials of trifluorotoluene and 1,2,4-trifluorobenzene cannot be measured by cyclic voltammetry; they exceed the solvent windows of MeCN and DMF ( $>3.0 \mathrm{~V}$ vs. SCE). This reflects the remarkable oxidizing power of TdCBPA ${ }^{++}$'s excited state. 
Table 5. e-PRC C-H heteroamination using TdCBPA.
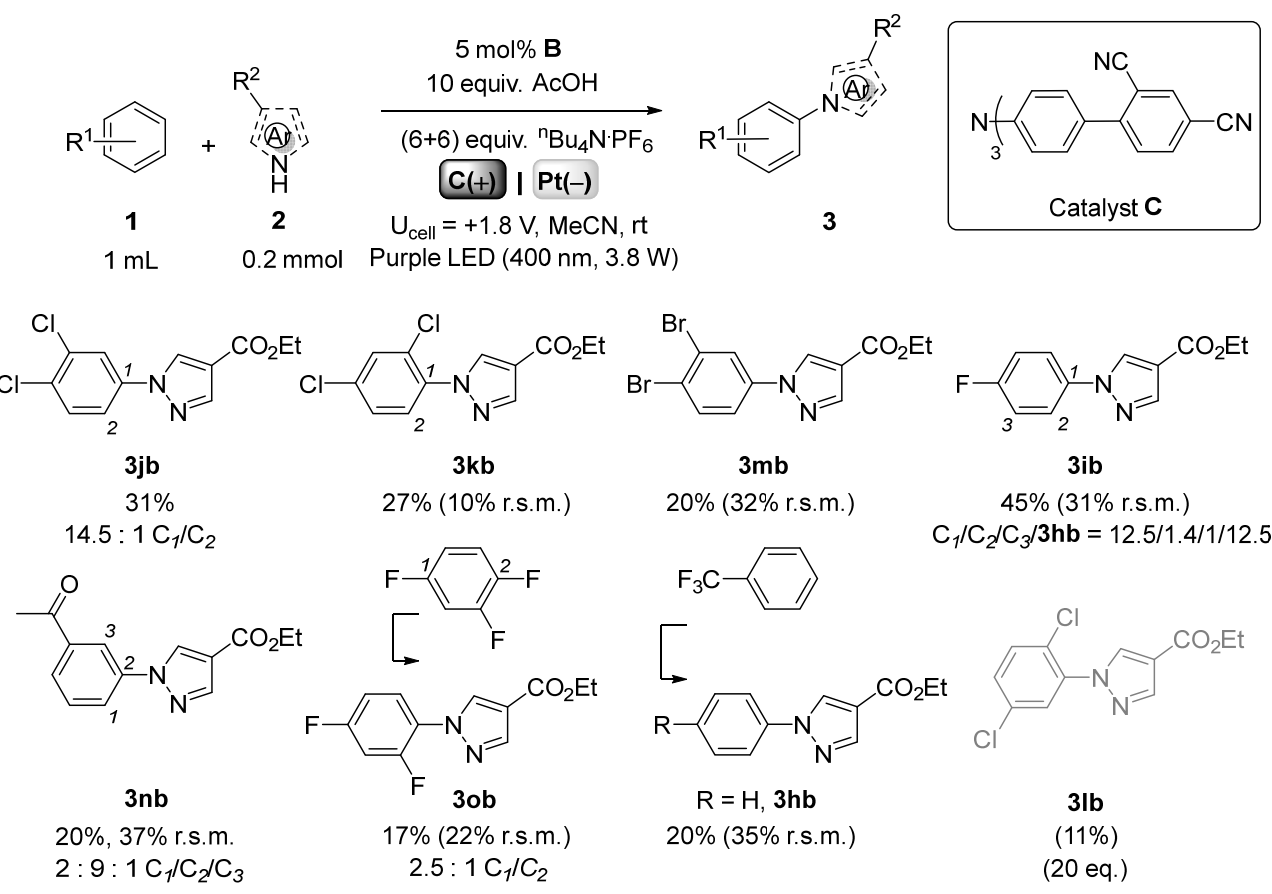

3ib

$45 \%(31 \%$ r.s.m.)

$45 \%(31 \%$ r.s.m. $)$
$\mathrm{C}_{1} / \mathrm{C}_{2} / \mathrm{C}_{3} / 3 \mathbf{h b}=12.5 / 1.4 / 1 / 12.5$

$: 9: 1 \mathrm{C}_{1} / \mathrm{C}_{2} / \mathrm{C}_{3}$

Isolated yields. Yields in parenthesis determined by ${ }^{1} \mathrm{H}$ NMR.

An intriguing theme running through the TPA-mediated e-PRC substrate scope is the apparent influence of steric effects on reactivity. In contrast to a previous report (45) and in line with the trends observed in Table 2, product yields increased as a function of the substitution pattern on dichloroarenes $(1,4-<1,3-\leq 1,2$-dichlorobenzene). This was surprising, given the corresponding increasing order of $E^{\mathrm{p}}$ ox $(1,4-<1,2-\leq 1,3$-dichlorobenzene).

Mechanistic studies Spectroelectrochemical analysis of TpBPA (Figure 5) TCBPA and TdCBPA (see Supplementary Information) revealed the formation of their respective $\mathrm{TPA}^{+} \mathrm{s}$ by the disappearance of the TPA band $\left(\lambda_{\max }=c a .345 \mathrm{~nm}\right)$ and appearance of two broad absorption bands between $360-430 \mathrm{~nm}\left(\lambda_{\max }=c a .420 \mathrm{~nm}\right)$ and between $600-900 \mathrm{~nm}\left(\lambda_{\max }=c a .719,856 \mathrm{~nm}\right)$, when the potential was increased from 0 to $+1.3 \mathrm{~V}$. Excellent reversibility was observed upon returning the potential to $+0.0 \mathrm{~V}$, indicating high stability of the TPA. ${ }^{+}$s as e-PRCats. While TpBPA is a white solid that does not absorb $400 \mathrm{~nm}$ light, it possesses a strong absorption at $\lambda_{\max }=365 \mathrm{~nm}$, where $\mathbf{T} \boldsymbol{p} \mathbf{B P A}{ }^{+}$ absorbs poorly. Performing our optimized synthetic procedure for 3aa with $365 \mathrm{~nm}$ LEDs afforded only 11\%, suggesting photoexcitation of neutral TpBPA is not a dominant factor in the mechanism. The aforementioned control reaction without applied potential afforded only $4 \%$ of $\mathbf{3 a a}$. In contrast 
to TpBPA, TCBPA is a pale yellow solid that does absorb appreciably at $400 \mathrm{~nm}$. Nevertheless, in the absence of an applied potential for the optimized synthesis of $\mathbf{3 g b}$, only a $12 \%$ yield of $\mathbf{3 g b}$ was observed. The detection of small amounts of product in the aforementioned control reactions corroborates a conPET-type mechanism (13-17) where photoexcitation of TpBPA or TCBPA leads to SET reduction of protons or trace $\mathrm{O}_{2}$ (reactions were bubbled by $\mathrm{N}_{2}$ for 5 min during preparation and sealed; no further strict precautions were taken) to generate the corresponding TPA ${ }^{+}$. In any case however, the very substantial yield differences when applied potential is present or absent confirm the pivotal role of the $\mathrm{TPA}^{+} \mathrm{s}$ and that e-PRC is the main product-forming pathway in both reactions.
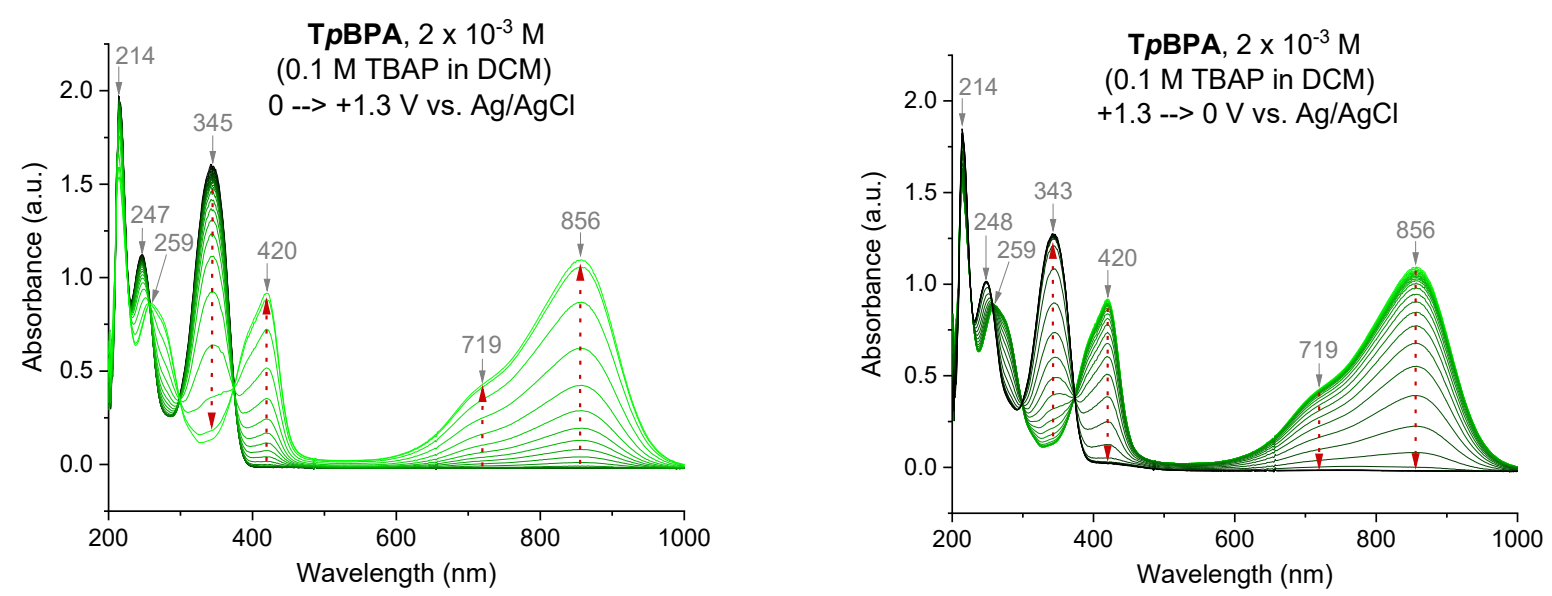

Figure 5. Spectroelectrochemistry of TpBPA, 0 to $+1.3 \mathrm{~V}$ vs. $\mathrm{Ag} / \mathrm{AgCl}$ (left) and +1.3 to $0 \mathrm{~V}$ (right).

Inspecting the UV-visible absorption spectra of $\mathbf{T} \boldsymbol{p} \mathbf{B P A}^{{ }^{+}}$and $\mathbf{T C B P A}{ }^{+}$, we reasoned that the longest wavelength bands ( $\lambda_{\max }$ at $c a .719$ and $856 \mathrm{~nm}$, respectively) must contain their $\mathrm{D}_{0} \rightarrow \mathrm{D}_{1}$ transitions. Based on the chemist's interpretation of Kasha's rule that prohibits photochemistry from higher order excited states, we therefore irradiated the reactions forming $\mathbf{3 a a}$ and $\mathbf{3 g b}$ with commercially-available LEDs at $740 \mathrm{~nm}$ and $850 \mathrm{~nm}$ and were mystified to observe no reaction in either case (Figure 6). That successful reaction was only observed at $400 \mathrm{~nm}$ implicated anti-Kasha behavior; a higher-order excited state participated in SET photooxidation. Such behavior is as surprising as it is intriguing, since i) not only are examples of photochemistry violating (the photochemical interpretation of) Kasha's rule rarely reported in organic synthesis $(15,17,70-71)$ but ii) the reported lifetimes of photoexcited radical ion species are already ultrashort. (72-73) In fact, despite a number of conPET/e-PRC reports invoking their photochemistry in 
super-oxidations/reductions, the question of how photoexcited radical ion species could ever participate in photochemical processes has remained elusive, given the ultrashort lifetimes of these species which lie beneath the timescales of diffusion/bimolecular quenching. $(15,17)$
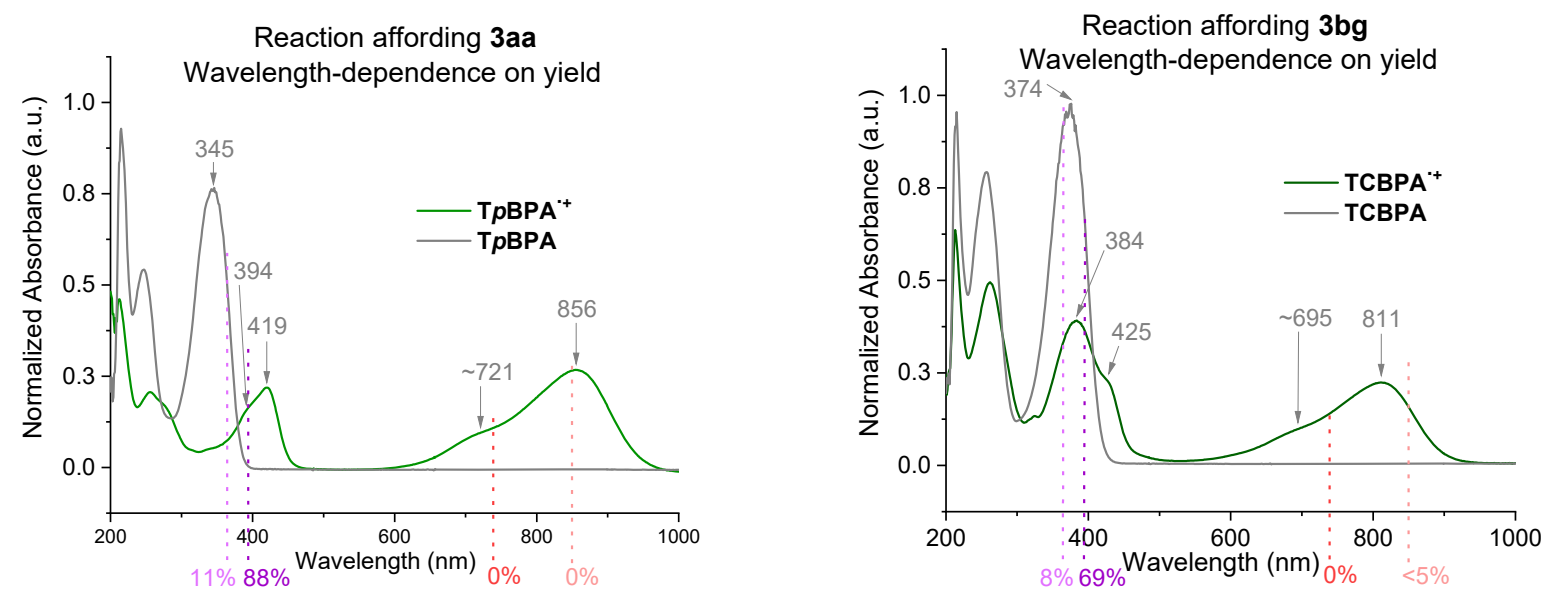

Figure 6. Wavelength dependence on product yields.

Greatly aiding our mechanistic study of this phenomenon was the fact that $\mathrm{TPA}^{\cdot+} \mathrm{s}$ can be preparatively isolated as their bench stable $\mathrm{PF}_{6}$ salts. (65) Their XRD crystal structures revealed a common propeller-type structure, also observed for parent TPAs (Figure 7). However, attempts to investigate quenching of photoexcited $\mathrm{TPA}^{\cdot{ }^{+} \mathrm{s}}$ were thwarted by the fact that they do not exhibit steady-state fluorescence (see Supplementary Information). Consistent with this observation, the reported lifetimes of related excited $\mathrm{N}$ radical cation species (74-76) lie within the femto- to picosecond timeframe. As a result, transient absorption spectroscopy (TAS) was employed to determine the lifetimes of excited TpBPA${ }^{+}$and TCBPA ${ }^{+}$. Pumping with a broadband visible light source $(490-900 \mathrm{~nm})$ revealed a ground state bleach in the $600-850 \mathrm{~nm}$ bands (Figure 8) and an excited state absorption between $490-570 \mathrm{~nm}$, indicative of absorption by the $\mathrm{D}_{1}$ (or $\mathrm{D}_{2}$ ) excited states. The lifetimes of the $\mathrm{D}_{1}$ excited states of $\mathbf{T p B P A}^{+}$and $\mathbf{T C B P A}^{+}$were $4.6 \mathrm{ps}$ and $8.6 \mathrm{ps}$, respectively, clearly ruling out photochemistry by diffusion-control and bimolecular quenching. It is reasonable to assume that higher order excited states possess even shorter lifetimes, and that precomplexation can therefore be the only rationalization for productive, unimolecular SET and the aforementioned anti-Kasha behaviour. 

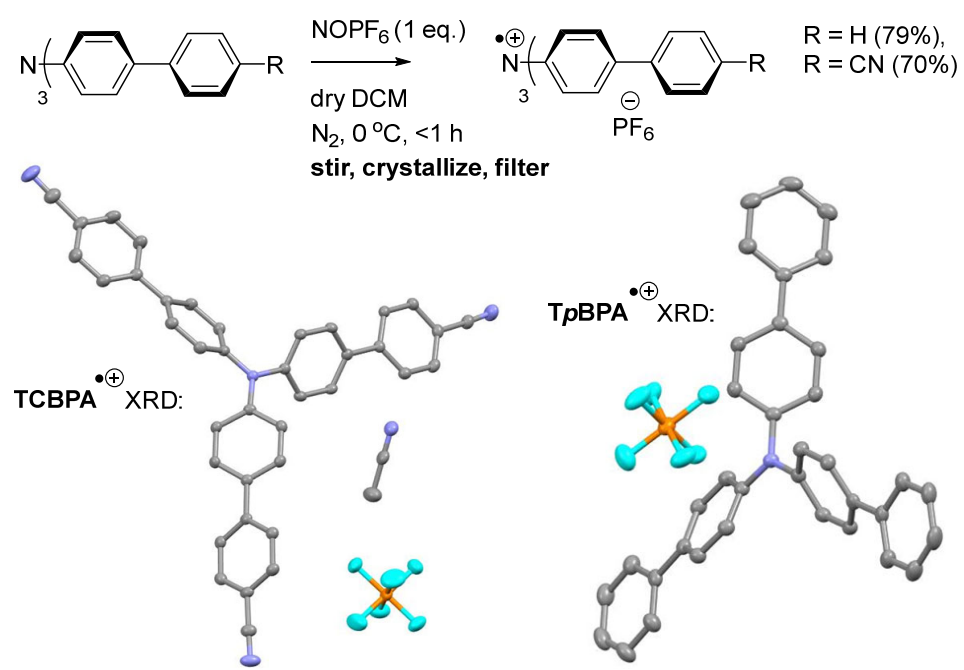

Figure 7. Synthesis of TpBPA ${ }^{+}$, TCBPA. ${ }^{+}$and their XRD crystal structures. Thermal ellipsoids are set at the 50\% probability level. Hydrogen atoms are omitted for clarity. $\mathrm{C}$ atoms shown in grey, $\mathrm{F}$ atoms in cyan, $\mathrm{N}$ atoms in blue, and $\mathrm{P}$ atoms in orange.

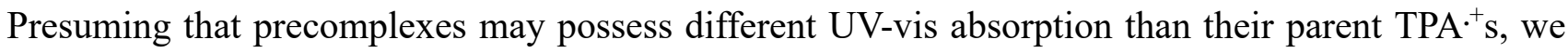
investigated quenching of the absorption of $\mathrm{TPA}^{+} \mathrm{s}$ in the presence of representative concentrations of arenes (Figure 9). In the presence of mesitylene, the spectrum of $\mathbf{T p} \mathbf{B P A}^{+}$was unchanged. Gratifyingly, irradiation with $400 \mathrm{~nm}$ light effected gradual conversion of $\mathbf{T p B P A}^{+}$to $\mathbf{T} \boldsymbol{p} \mathbf{B P A}$, corroborating the expected SET from mesitylene to the photoexcited TPA ${ }^{+}$. Interestingly and in contrast, the spectrum of TCBPA $^{+}$was altered by addition of $\mathrm{PhCl}$; a small bathochromic perturbation of the peak at $384 \mathrm{~nm}$ to $395 \mathrm{~nm}$ occurred, indicating complexation between TCBPA$^{+}$ and $\mathrm{PhCl}$. Irradiation with $400 \mathrm{~nm}$ led to complete conversion of TCBPA${ }^{+}$to TCBPA after 5 min. Given the paramagnetic nature of these species, we reasoned that a change in the EPR spectra of $\mathrm{TPA}^{+} \mathrm{s}$ in the presence of arene substrates (350 eq., mirroring the reaction conditions) would be more conclusive in corroborating precomplexation. 
(a) TAS of TpBPA.+ at different time delays

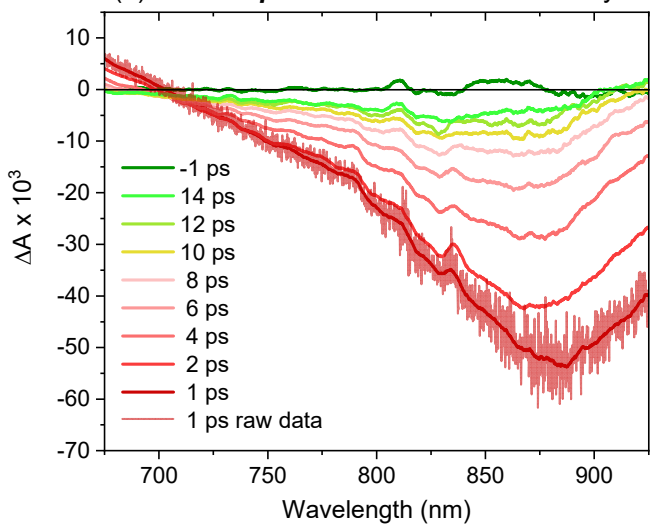

(c) TAS of TCBPA ${ }^{+}$at different time delays

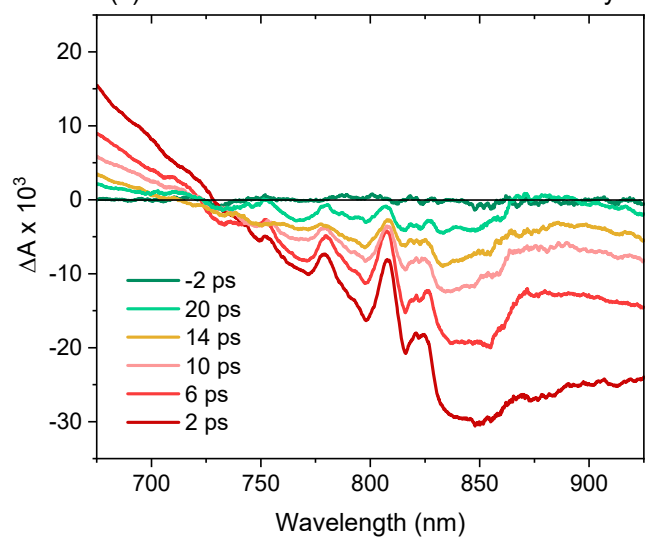

(b) Decay-associated spectra of TpBPA *+

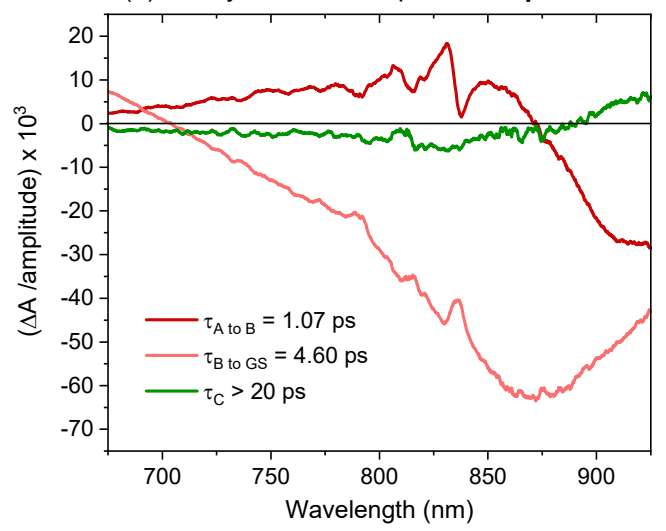

(d) Decay-associated spectra of TCBPA ${ }^{+}$

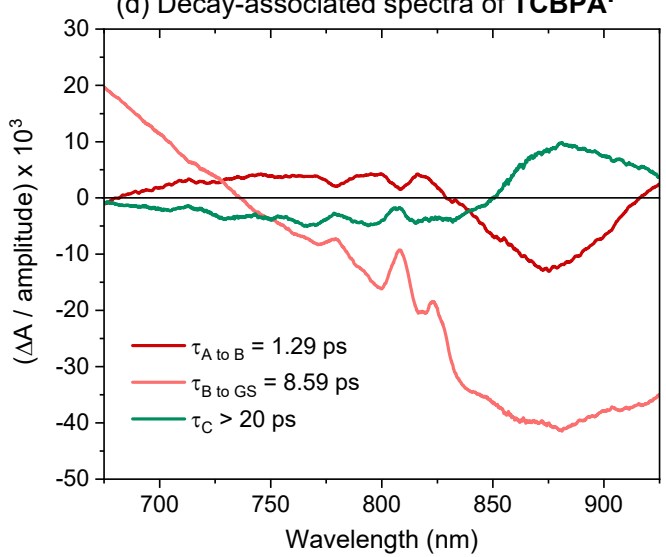

Figure 8. Transient absorption and decay-associated spectra of $\mathbf{T} p \mathbf{B P A}^{{ }^{+}}$and $\mathbf{T C B P A}{ }^{+}$. Data were treated with a smoothing function for visualization, see Supplementary Information for raw data.
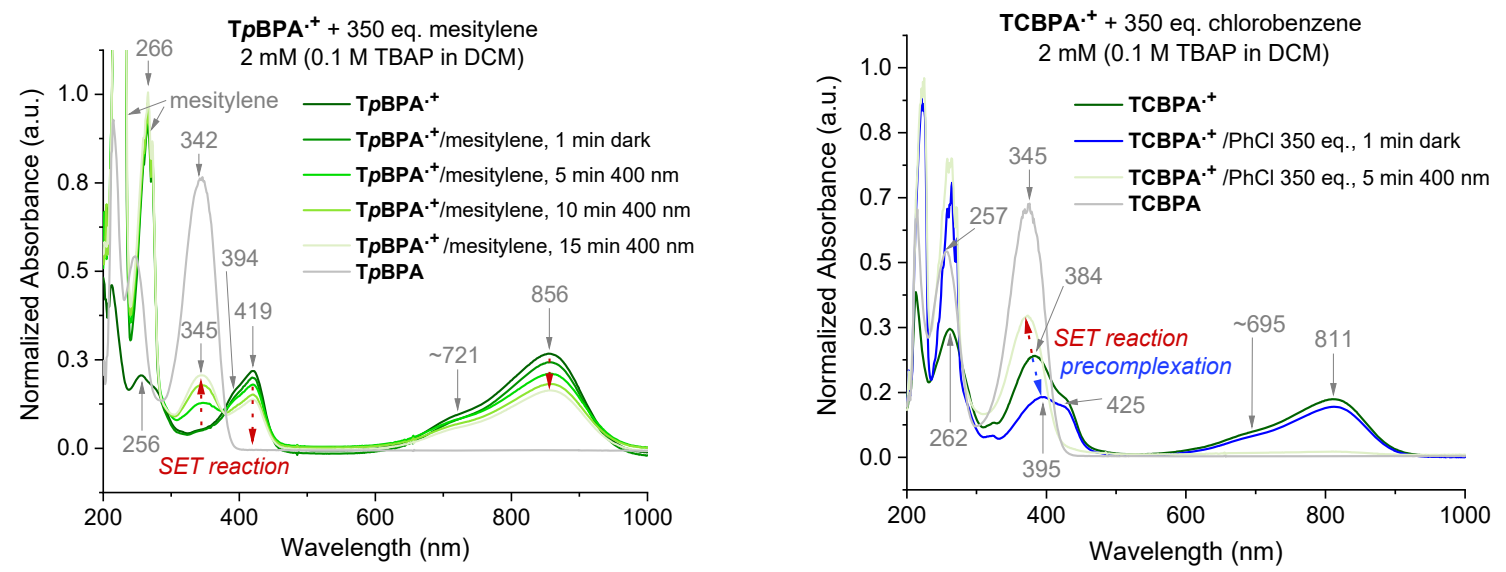

Figure 9. UV-vis spectroscopy of $\mathbf{T p} \mathbf{B P A}^{+}{ }^{+}$(left) and $\mathbf{T C B P A} .^{+}$(right) in the presence of mesitylene and $\mathrm{PhCl}$, respectively and after irradiation at $400 \mathrm{~nm}$. 
The EPR signal of $\mathbf{T} \boldsymbol{p} \mathbf{B P A}^{+}$showed a triplet $\left(a_{\mathrm{N}}=8.9 \mathrm{G}\right)$. Addition of mesitylene to $\mathbf{T} \boldsymbol{p} \mathbf{B P A} \mathbf{A}^{+}$caused its EPR signal to shift ( $\Delta B=4.5 \mathrm{G})$ to lower $\mathrm{G}$ values (Figure 10), but the signal shape was largely unchanged. This indicates that the spin density of the $\mathbf{T p B P A}^{+}$is largely unaffected when it undergoes precomplexation with mesitylene. A less pronounced shift in $G$ value occurred in the presence of iodobenzene $(\Delta B=2.0 \mathrm{G})$ but flattening of the triplet shoulders was observed (see Supplementary Information for detailed discussion). Based on these spectroscopic differences, we hypothesize that a different type of precomplex must occur in this case that is unreactive, to rationalize the inability to engage this substrate under the reaction conditions despite its more accessible redox potential $\left(E^{\mathrm{p}}{ }_{\mathrm{ox}}=+2.07\right.$ vs. SCE) than toluene $\left(E_{\mathrm{ox}}^{\mathrm{p}}=+2.28 \mathrm{~V}\right.$ vs. SCE). (77) In contrast to TpBPA ${ }^{+}$, simulated fitting of the EPR signal from TCBPA $^{{ }^{+}}$revealed two radical species, one triplet and one superimposed singlet appearing as a large broad central feature. We presume that this particular $\mathrm{TPA}^{+}$exists as a mixture of rotamers in solution, one propeller-type as observed in the solid state, and one in which a biphenyl unit falls into conjugation with the $\mathrm{N}$ radical cation, consistent with reported behaviour for similar compounds. (78-80) Addition of $\mathrm{PhCl}$ caused a notable change in the signal shape, giving exclusively the triplet signal (Figure 11), consistent with the change in UV-vis (Figure 9) and indicating that the spin density of TCBPA ${ }^{+}$is notably affected by precomplexation with $\mathrm{PhCl}$. A similar change was detected upon addition of 1,2-dichlorobenzene, but not for its 1,4-congenor (17\% yield of $3 \mathbf{j b}$ vs. $6 \%$ yield of $3 \mathbf{l b}$ under TCPBA e-PRC) and not for $\mathrm{PhBr}(22 \%$ of $\mathbf{3 f b}$ from TCPBA e-PRC) which instead all gave spectra clearly favoring the unreactive complex (singlet signal).
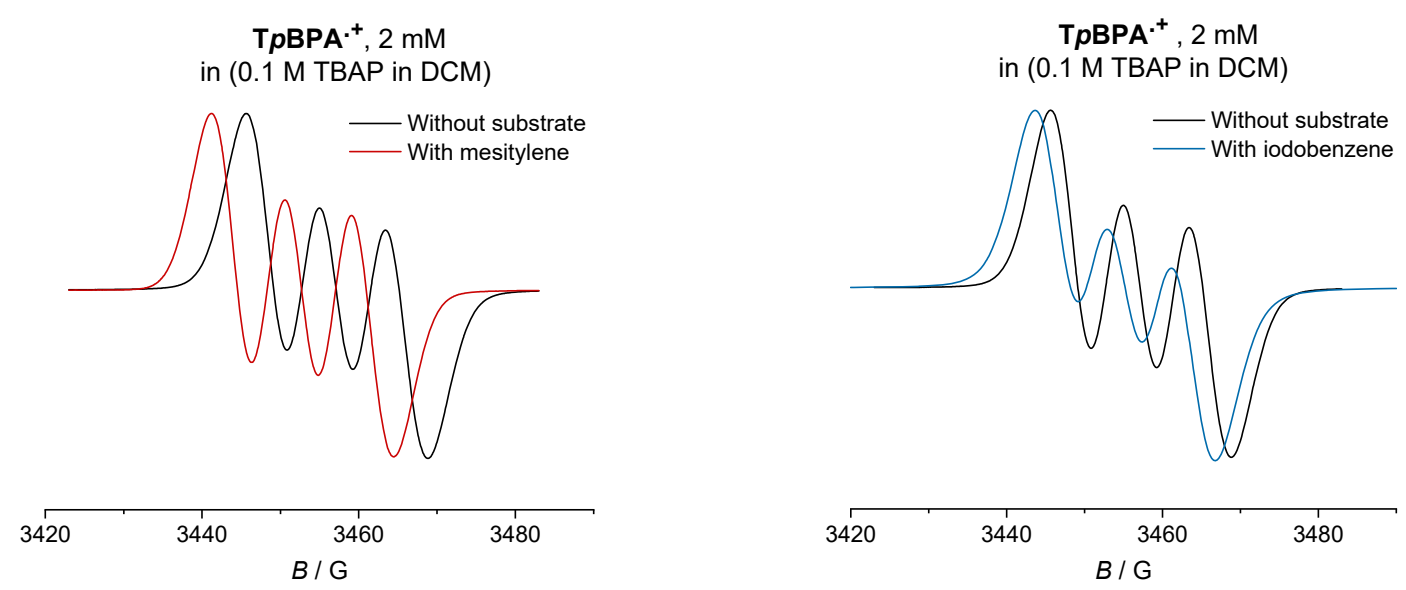

Figure 10. EPR spectra of $\mathbf{T p B P A}^{+}$with reactive mesitylene (left, 350 eq.) and unreactive iodobenzene (right, 350 eq.). 

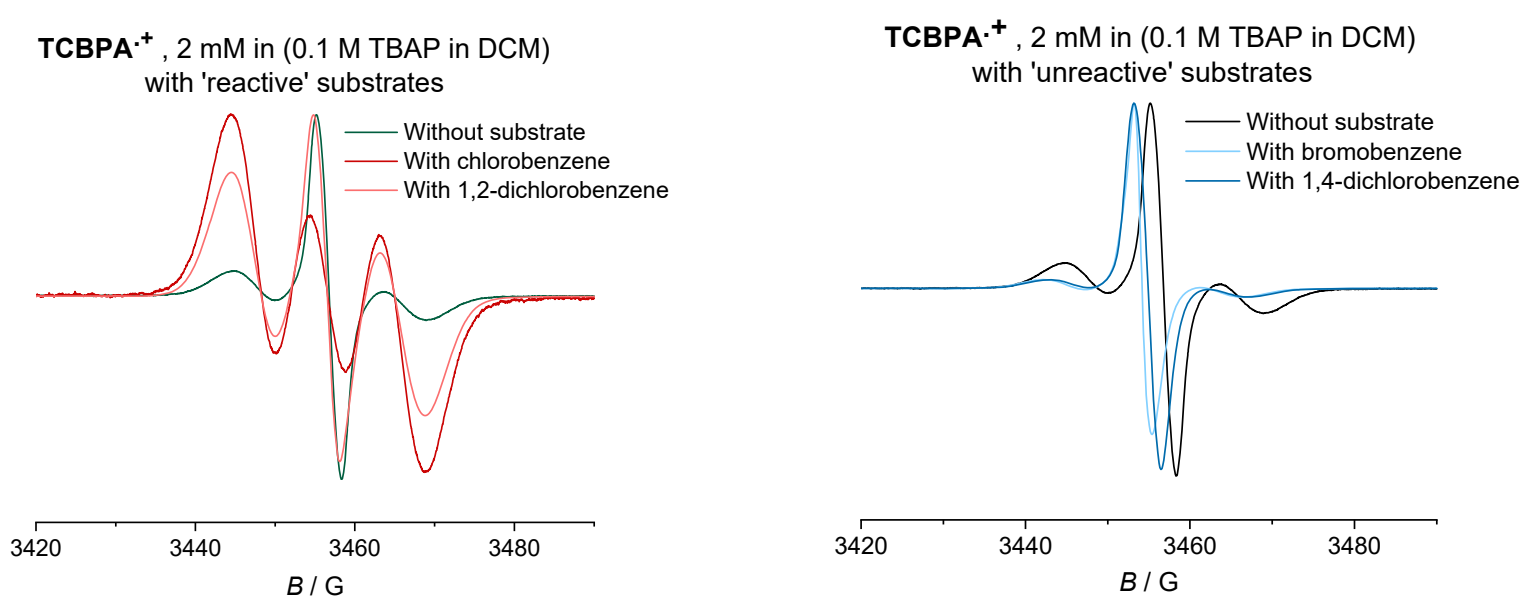

Figure 11. EPR spectra of the TCBPA $^{+}$with reactive (left) vs. unreactive (right) substrates (350 eq.).

To shed further light on the spectroscopic observations, Density Functional Theory (DFT) calculations were employed to model precomplexation of various TPA ${ }^{+} /$arene combinations (Table 6). For unsymmetrical (halo)arene substrates, orientations of the complex with halogen facing both 'in' to the $\mathrm{N}$ radical cation and 'out' were explored (see Supplementary Information for full investigations). We assumed that $\pi$-stacking interactions (81-82) at the TPA.+'s biphenyl unit could be responsible for precomplexation. Attempts to position $\mathrm{PhCl}$ or mesitylene substrates in a sandwich or parallel-displaced $\pi-\pi$ stacking interaction (" $\pi-\pi$ " complex) around the inner N-bearing ring of their respective $\mathrm{TPA}^{\cdot{ }^{+} \mathrm{s}}$ led predominantly to dissociation, whereas positioning of the substrates around the terminal aromatic ring identified a local minima for the complexes resembling a T-type stacking interaction ("T- $\pi$ " complex). For this complex, minimal change in the spin density was detected for TpBPA ${ }^{+}+$mesitylene (Figure 12), whereas a large shift in spin density occurred for TCBPA $^{+}+\mathrm{PhCl}$ where the $\mathrm{Cl}$ atom was facing inwards (Figure 13). This is consistent with the changes in EPR and UV-vis spectra, and so we assigned this "T- $\pi$ " complex as the one responsible for the triplet EPR signal and successful reactivity, since the oxidizing power of the $\mathrm{N}$ radical cation remains localized on its $\mathrm{N}$ atom. On the other hand, for less successful substrate $\mathrm{PhBr}$ and unsuccessful $\mathrm{PhI}$ (no product, $60 \% \mathbf{2 b}$ recovered), a " $\pi-\pi$ ” complex was presumed to be responsible for the broad singlet EPR signal. Delocalization of the $\mathrm{N}$ radical cation over the biphenyl aromatic system would lead to stabilization, presumably decreasing $E^{\mathrm{p}}$ ox of the photoexcited TPA ${ }^{+}$. 
Table 6. Free energies and intermolecular distances for T- $\pi$ or $\pi-\pi$ precomplexes.

\begin{tabular}{|c|c|c|c|c|}
\hline \multirow{2}{*}{ Complex ${ }^{\mathrm{a}}$} & \multicolumn{2}{|c|}{ Complexation $\Delta \mathrm{G}\left(\mathrm{kcal} \mathrm{mol}^{-1}\right)$} & \multicolumn{2}{|c|}{ Intermolecular distance $(\AA)$} \\
\hline & $\mathrm{T}-\pi$ & $\pi-\pi$ & $\mathrm{T}-\pi$ & $\pi-\pi$ \\
\hline $\begin{array}{c}\text { TpBPA. } \\
+1,3,5-\mathrm{TMB}\end{array}$ & $+7.2^{\mathrm{b}}$ & $+4.9^{\mathrm{c}, \mathrm{f}}$ & $3.3-5.5^{\mathrm{b}}$ & $3.6-4.2^{\mathrm{c}, \mathrm{f}}$ \\
\hline $\mathbf{T p} \mathbf{B P A}^{+^{+}+\mathrm{PhI}}$ & $\begin{array}{l}+28.4^{\mathrm{b}, \mathrm{d}} \\
+28.1^{\mathrm{b}, \mathrm{e}} \\
+4.5^{\mathrm{b}, \mathrm{d}}\end{array}$ & $\begin{array}{l}+28.3^{\mathrm{b}, \mathrm{d}} \\
+26.1^{\mathrm{b}, \mathrm{e}}\end{array}$ & $\begin{array}{l}4.7-6.5^{\mathrm{b}, \mathrm{d}} \\
3.8-6.2^{\mathrm{b}, \mathrm{e}} \\
4.5-6.8^{\mathrm{b}, \mathrm{d}}\end{array}$ & $\begin{array}{l}5.2-5.5^{\mathrm{b}, \mathrm{d}} \\
6.2-6.8^{\mathrm{b}, \mathrm{e}}\end{array}$ \\
\hline TCBPA $^{+}+\mathrm{PhCl}$ & $\begin{array}{l}+3.5^{\mathrm{c}, \mathrm{d}} \\
+5.1^{\mathrm{b}, \mathrm{e}}\end{array}$ & $+2.9^{\mathrm{c}, \mathrm{e}, \mathrm{f}}$ & $\begin{array}{l}3.2-5.3^{\mathrm{c}, \mathrm{d}} \\
4.8-7.4^{\mathrm{b}, \mathrm{e}}\end{array}$ & $3.7-4.3^{\mathrm{ce}, \mathrm{f}}$ \\
\hline TCBPA $^{+}+\mathrm{PhBr}$ & $\begin{array}{l}+30.8^{\mathrm{b}, \mathrm{d}} \\
+31.4^{\mathrm{b}, \mathrm{e}}\end{array}$ & $\begin{array}{l}29.7^{b, d} \\
\text { N.D. }\end{array}$ & $\begin{array}{l}3.4-6.2^{\mathrm{b}, \mathrm{d}} \\
3.7-6.9^{\mathrm{b}, \mathrm{e}}\end{array}$ & $\begin{array}{c}4.9-5.4^{\mathrm{b}, \mathrm{d}} \\
\text { N.D. }{ }^{\mathrm{b}, \mathrm{e}}\end{array}$ \\
\hline TCBPA $^{+}$ & $+4.5^{\mathrm{b}, \mathrm{d}}$ & $+6.6^{\mathrm{b}, \mathrm{d}}$ & $4.2-6.4^{\mathrm{b}, \mathrm{d}}$ & $5.3-5.7^{\mathrm{b}, \mathrm{d}}$ \\
\hline$+1,2 \mathrm{PhClCl}$ & $+4.7^{\mathrm{b}, \mathrm{e}}$ & N.D. ${ }^{b, e}$ & $4.6-6.9^{\mathrm{b}, \mathrm{e}}$ & N.D. ${ }^{\text {b,e }}$ \\
\hline TCBPA $^{+}$ & $+4.9^{\mathrm{b}, \mathrm{d}}$ & N.D. ${ }^{b, d, g}$ & N.D. ${ }^{b, d}$ & N.D. ${ }^{b, d, g}$ \\
\hline$+1,3 \mathrm{PhClCl}$ & $+5.2^{\mathrm{b}, \mathrm{e}}$ & N.D. ${ }^{b, e, g}$ & $4.9-7.4^{\mathrm{b}, \mathrm{e}}$ & N.D. ${ }^{b, e, g}$ \\
\hline $\begin{array}{c}\text { TCBPA }^{+} \\
+1,4 \mathrm{PhClCl}\end{array}$ & N.D. ${ }^{b, g}$ & $+4.2^{\mathrm{b}, \mathrm{d}}$ & N.D. ${ }^{b, g}$ & $5.5-5.8^{\mathrm{b}, \mathrm{d}}$ \\
\hline
\end{tabular}

N.D. not determined; these complexes could not be converged or dissociated. In all cases, a solvent of MeCN was modelled implicitly. Pseudopotentials were applied to I and Br atoms (see Supplementary Information for details). Intermolecular distances quoted are not centroid-to-centroid of the arene rings and are defined in the Supplementary Information. ${ }^{a}$ Hypothesized orientation of the precomplex that matches with UV-vis/EPR data and

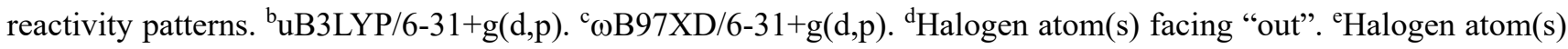

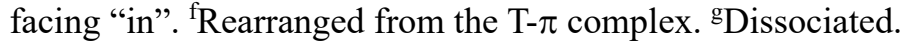

Free energies of precomplexation were all found to be endergonic at the level of theory employed, (83-84) intermolecular distances for T- $\pi$ stacking and $\pi-\pi$ stacking were close to previously-reported distances for simpler complexes/dimers. (83-89) Mesitylene, chlorobenzene, 1,2-dichlorobenzene and their respective TPA ${ }^{+} \mathrm{s}$; for which the 'reactive' T- $\pi$ complex was predicted by EPR studies; all had accessible $\Delta \mathrm{G}$ values $\left(+3.5-7.2 \mathrm{kcal} \mathrm{mol}^{-1}\right)$. An accessible $\Delta \mathrm{G}$ value was also found for 1,3-dichlorobenzene $\left(+4.9-5.2 \mathrm{kcal} \mathrm{mol}^{-1}\right)$ consistent with its reactivity $(20 \% \mathbf{3 k b}$ under the TCBPA e-PRC of Table 4). Iodo- and bromobenzene as substrates gave very high $\Delta \mathrm{G}$ values for T- $\pi$ complexes and their $\pi-\pi$ complexes were more accessible albeit still highly endergonic. Attempts to obtain a T- $\pi$ complex for TCBPA $^{+}$with 1,4-dichlorobenzene led to dissociation, while its $\pi-\pi$ complex was found to be accessible. 

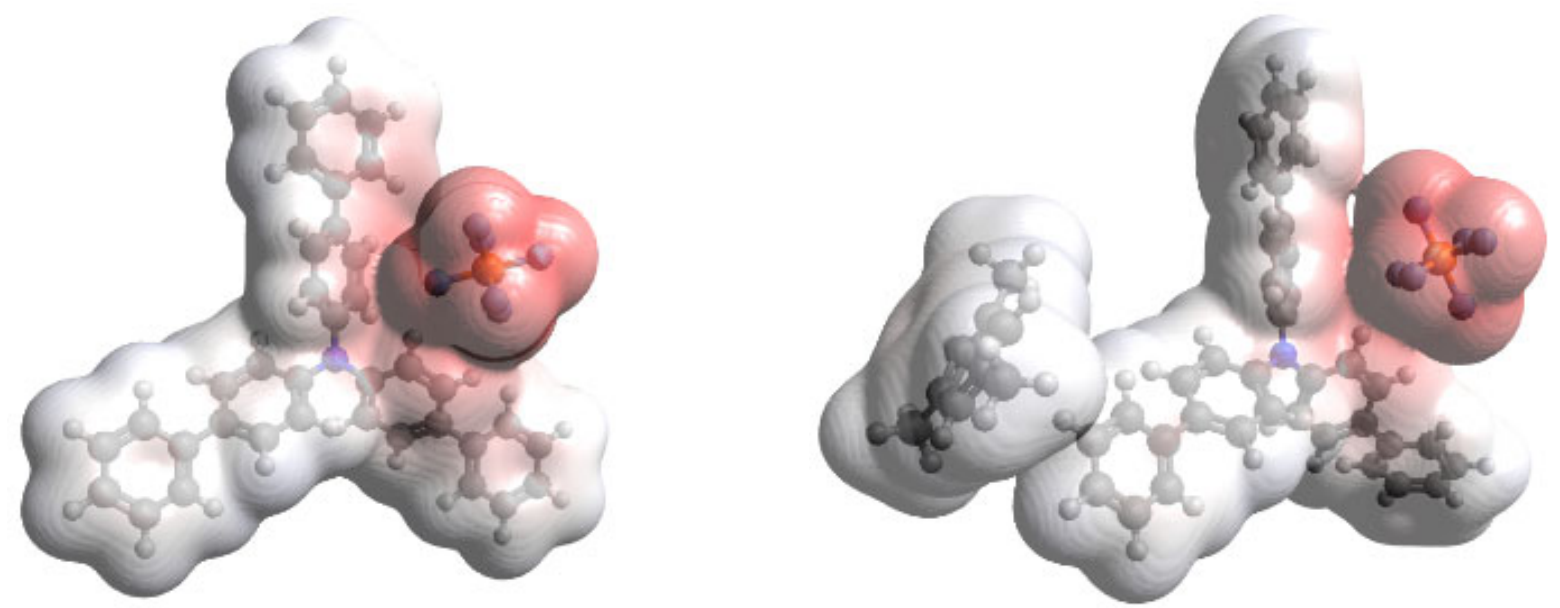

Figure 12. DFT spin densities of TpBPA. ${ }^{+}$without (left) vs. with (right) mesitylene, T- $\pi$ complex.
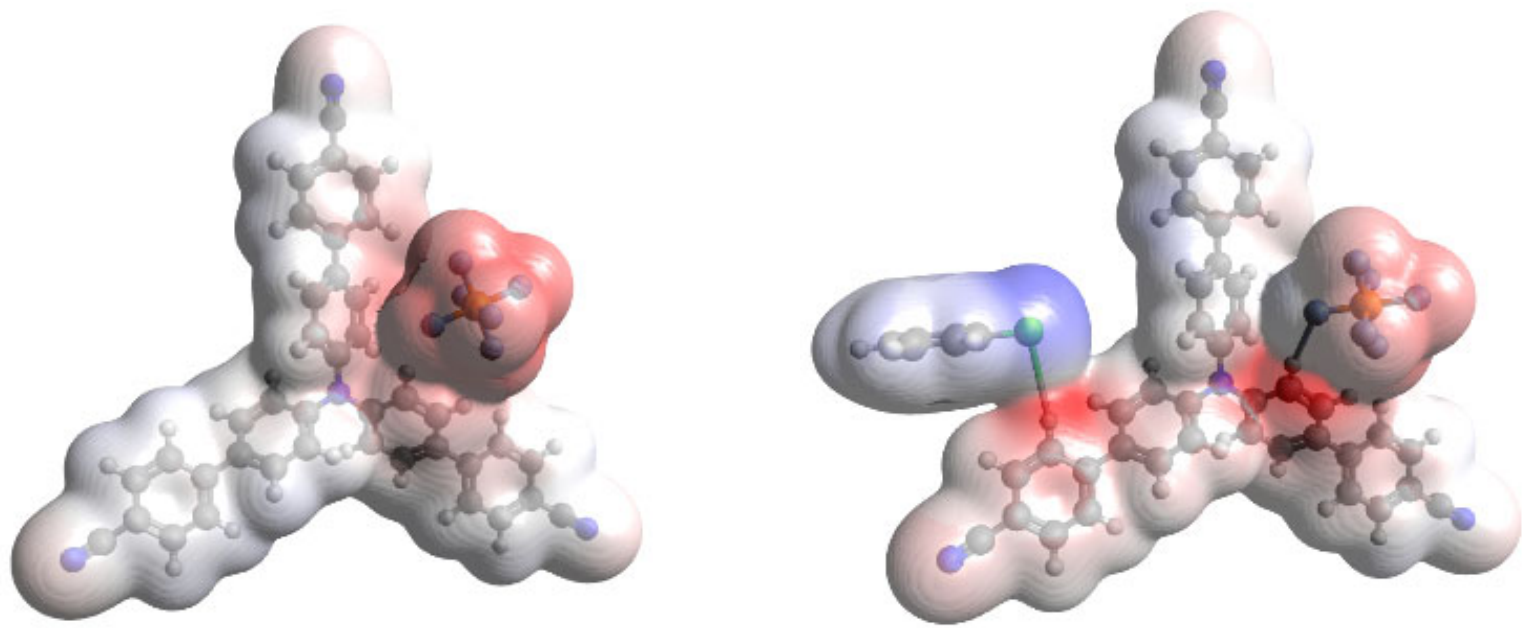

Figure 13. DFT spin densities of TCBPA$^{++}$without (left) vs. with (right) $\mathrm{PhCl}, \mathrm{T}-\pi$ complex, $\mathrm{Cl}$ atom facing "in".

Time-dependent density functional theory (TD-DFT) calculations were then used to investigate the energies higher order excited $D_{n}$ states for $\mathbf{T p B P A}^{+}, \mathbf{T C B P A}^{+}$and $\mathbf{T d C B P A}^{+}$, using both CAM-B3LYP/6-31G(d,p) and wB97XD/6-31+G(d,p) (a solvent of MeCN or DCM was modelled implicitly, counterions were omitted). (74,90) The calculated UV-visible spectra of the radical cations of TpBPA. ${ }^{+}$and $\mathbf{T C B P A}{ }^{+}$in $\mathrm{MeCN}$ were in reasonable agreement with their experimental spectra (Figure 14). Since the broad visible band (ca. 580-850 nm) is known to result from symmetry breaking of the first excited state $\mathrm{D}_{E}$ in solution and in the excited state to give the $\mathrm{D}_{1}$ and $\mathrm{D}_{2}$ states (two overlapping bands), and TD-DFT calculations assumed only the propeller-type structure that converged, predictions of the 580-850 $\mathrm{nm}$ region were less accurate than for higher order excitations. (79) 

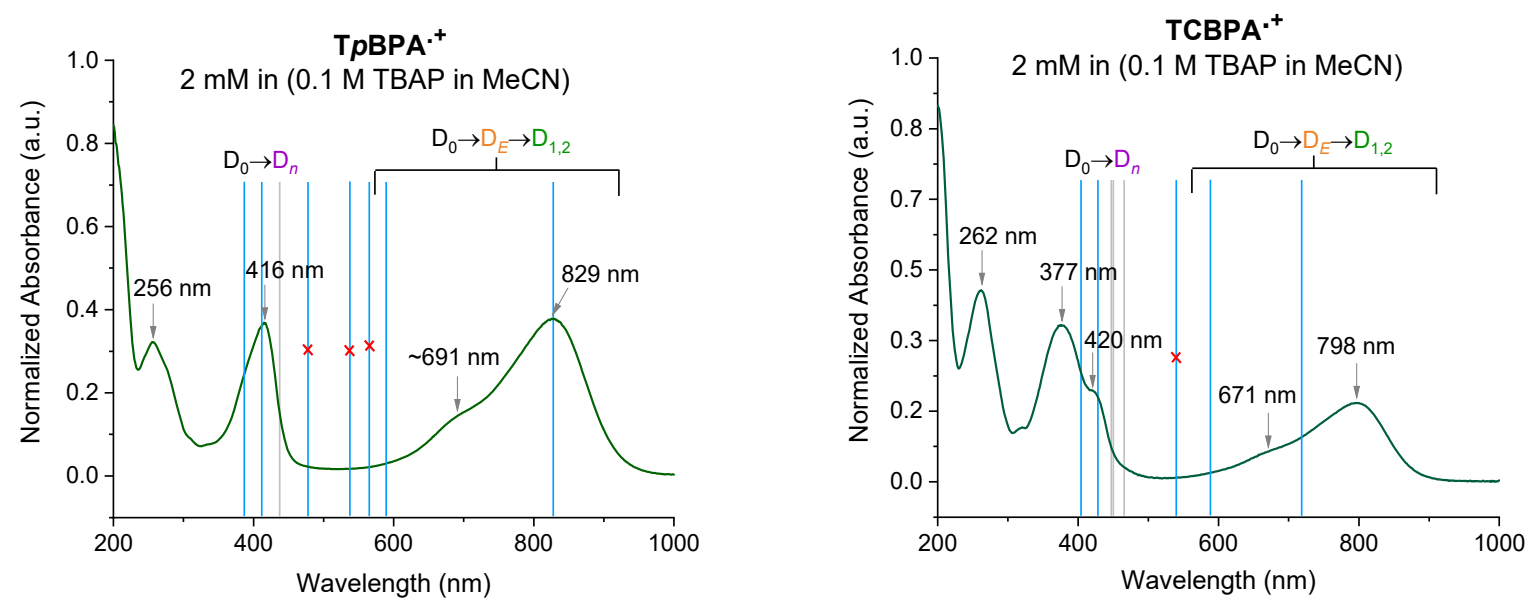

Figure 14. Computed (CAM-B3LYP/6-31G(d,p), $\mathrm{CPCM}=\mathrm{MeCN}$, blue lines) vs. experimental UV-vis spectra of TpBPA ${ }^{+}$and TCBPA $^{+}$in $\mathrm{MeCN}$ containing $0.1 \mathrm{M}^{\mathrm{n}} \mathrm{Bu} 4 \mathrm{~N} \cdot \mathrm{PF}$. Negligible TD-DFT exitations (coefficient $f<0.0010$ ) in grey. Assignments are based on the optical transitions.

Canonical molecular orbital (MO) calculations $(74,91)$ revealed that excited states involved HOMO- ' $n$ ' to SOMO transitions, typical of hole-particle excitations (Figure 15A). $(45,74)$ As was the case herein, canonical MOs for higher order excited states and for hole-particle excitations often present a substantial list of orbital transitions with similar coefficients without a single dominant component. Here, Natural Transition Orbitals (NTOs) are a helpful tool to visualize the changes in 'hole density' during transitions. (92) A common theme for all TPA. ${ }^{+}$s studied was that the first (and second) excited states $\left(\mathrm{D}_{0} \rightarrow \mathrm{D}_{E \rightarrow \mathrm{D}_{1,2}}\right)$ involved $\pi \rightarrow \pi^{*}$ transitions around the core aromatic rings, while the higher order excited states $\left(\mathrm{D}_{0 \rightarrow \mathrm{D}_{n}}\right)$ associated with the excitation wavelength of interest (395 $\mathrm{nm}$ ) involved $\pi \rightarrow \pi^{*}$ transitions around the peripheral aromatic rings (Figure 15B). It seems noteworthy that the concentration of 'hole density' at the peripheral aromatic rings is exactly where it would be in closest proximity to the arenes in reactive T- $\pi$ precomplexes.

Ruling out participation of the first two excited states and states accessed at wavelengths $<380 \mathrm{~nm}$, we predict 'effective maximum' excited state potentials of $\mathbf{T p} \mathbf{B P A}{ }^{+}$at $+4.02 \mathrm{~V}, \mathbf{T C B P A}^{+}$at $+4.19 \mathrm{~V}$ and TdCBPA $^{+}$at $+4.41 \mathrm{~V}$ vs. SCE from the Rehm-Weller equation. Although, naturally, a proportion of the excited state TPA.+'s energy will be dissipated by vibrational relaxation and solvent reorganization (observed by TAS, see Supplementary Information). 

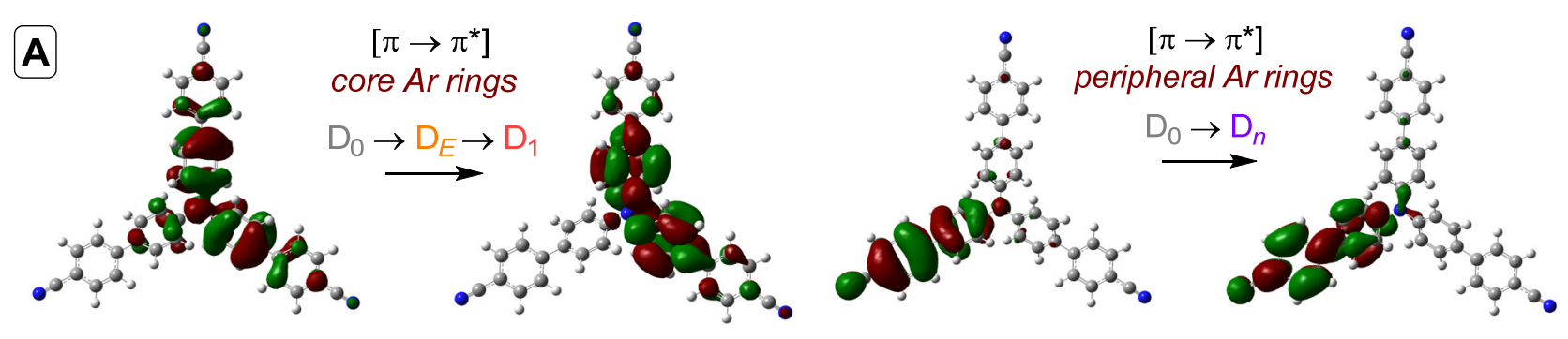

B
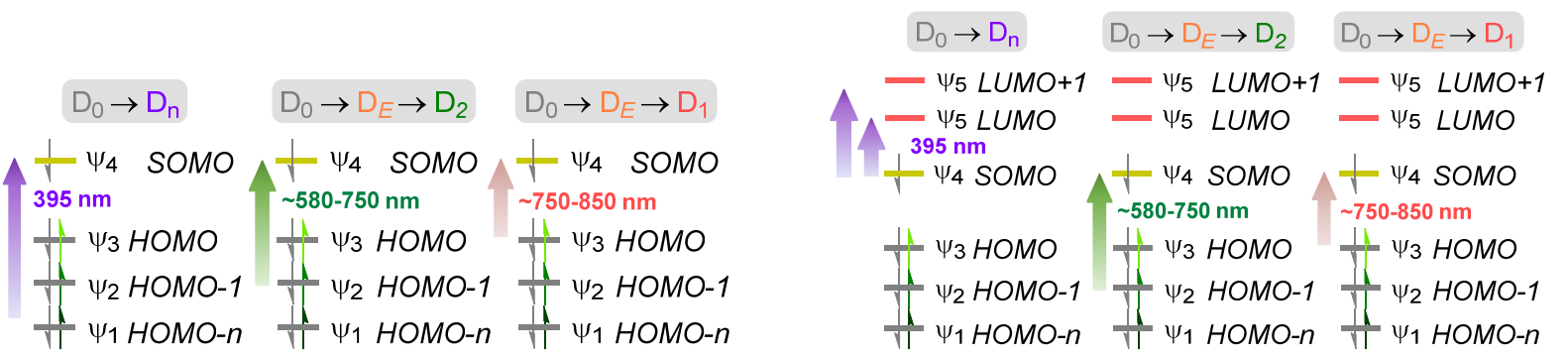

Figure 15. A. Natural Transition Orbitals (NTOs) depicting photoexcitation of TCBPA ${ }^{+}$to $D_{1}$ or $D_{n}$. B. TD-DFT predicted orbital transitions of TpBPA. ${ }^{+}$(left) and TCBPA$^{+^{+}}$(right). Wavelengths are derived from optical transitions.

A mechanism is proposed consistent with spectroscopic and computational studies herein (Figure 16). Anodic SET oxidation generates the TPA.+ from its TPA. Photoexcitation of the TPA. ${ }^{+}$to its $\mathrm{D}_{1} / \mathrm{D}_{2}$ or higher $\mathrm{D}_{n}$ states followed by bimolecular SET reductive quenching is prohibited by the $\mathrm{TPA}^{++}$s picosecond lifetime. Instead, preassociation occurs to give a reactive $\mathrm{T}-\pi$ or an unreactive $\pi-\pi$ precomplex, depending on the sterics of the arene substrate. In the latter case, conjugative stabilization of the $\mathrm{N}$ radical cation decreases $E^{\mathrm{p}}$ ox of the ${ }^{*} \mathrm{TPA}{ }^{+}$below the threshold for productive unimolecular SET such that photoexcitation leads simply to non-radiative photophysical relaxation processes (such as internal conversion). In the former case, photoexcitation yields unimolecular SET reductive quenching of the ${ }^{*} \mathrm{TPA}^{+}$, regenerating the TPA and generating the arene radical cation to be intercepted by the $N$-heterocyclic nucleophile $\mathbf{2 b}$ followed by loss of protons and further SET (anodic or by the $\mathrm{TPA}^{+}$) to yield product 3. The prerequisite for precomplexation rationalizes the typical requirement for an excess of arene (3.5 eq. up to $1 \mathrm{~mL}, \sim 40$ eq. herein) to drive precomplexation equilibrium in arene amination reactions mediated by radical cations (45-46). 


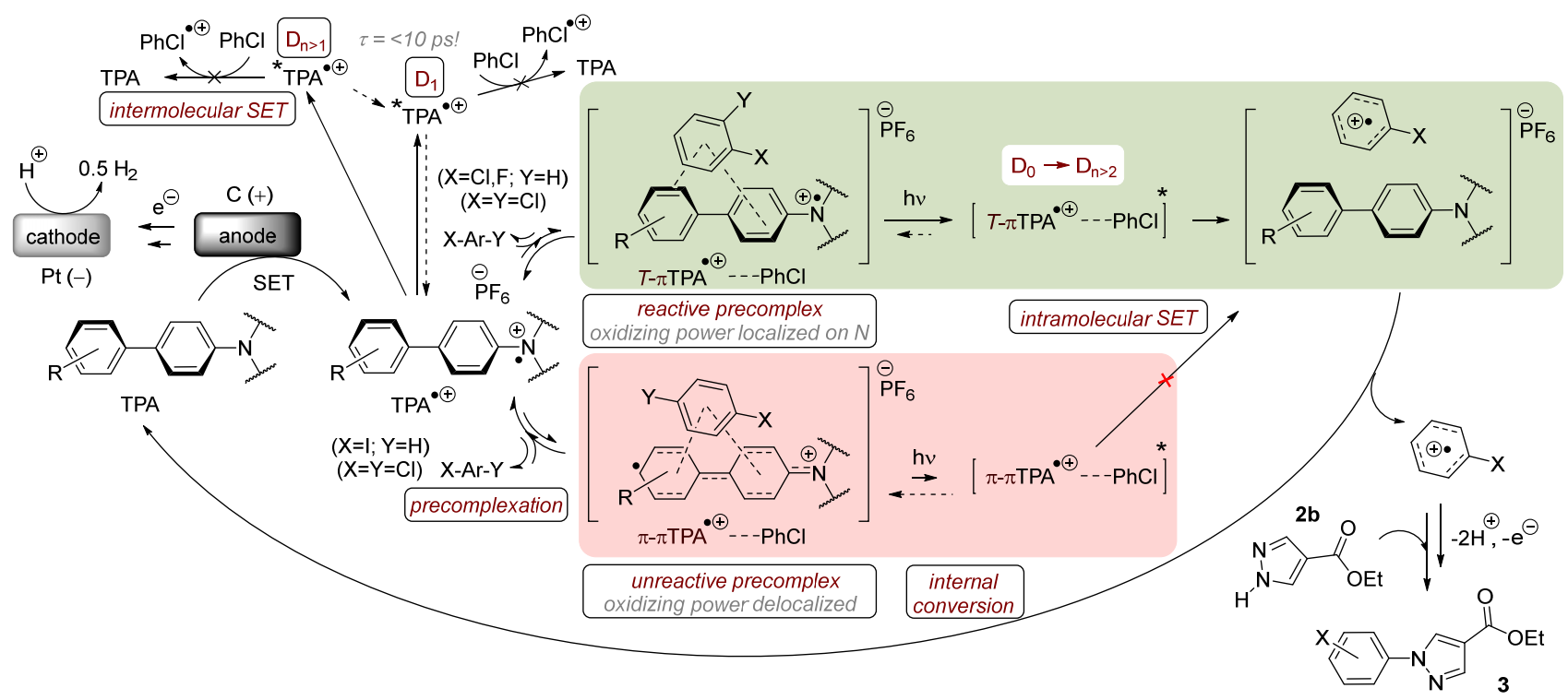

Figure 16. Proposed e-PRC mechanism involving precomplexation and higher order (than $\left.D_{1} / D_{2}\right)$ photoexcited states.

Conclusion In conclusion, we report tri(p-substituted)biarylamines (TPAs) as a novel class of tunable, electroactivated photoredox catalyst. Photoexcited tris( $p$-substituted $)$ biarylaminium radical cations $\left(\mathrm{TPAs}^{+}\right)$have been demonstrated as highly potent and tunable SET oxidants despite their ultrashort excited state lifetimes. As demonstrated herein, straightforward customization of neutral TPAs lends itself to the tuning of UV-vis absorptions, redox potentials and handles for Preassociative Photoredox Catalysis ('Pre-PRC') within the TPAs ${ }^{+}$. Wavelength-dependent control reactions and excited state potentials, as estimated by cyclic voltammetry and TD-DFT calculations, corroborate the participation of higher order (than $\mathrm{D}_{1} / \mathrm{D}_{2}$ ) excited states in the photochemistry. Precomplexation of $\mathrm{TPAs}^{+}$and arene substrates was evidenced by EPR spectroscopy, UV-vis spectroscopy and supported by DFT calculations. To our knowledge, this study constitutes an unprecedented example of dispersion interactions ( $\pi$-stacking) as a control element in photochemistry. In this way, Pre-PRC enabled remarkable photochemical phenomena: i) circumvention of the ultrashort lifetimes of excited radical ion states for their use in photocatalysis, ii) anti-Kasha fashion engagement of higher order excited states in photocatalysis, iii) overturning of thermodynamic selectivity dictated by redox potentials by virtue of steric/electronic factors involved in the precomplex. Phenomena (iii) is particularly an advantage over direct electrolysis, where electrodes typically discriminate between molecules based on redox potentials. In context of the findings herein, we foresee 'Pre-PRC' as an important next evolution of photoredox catalysis, that presents tremendous opportunities in novel 
reactivity and selectivity to the synthetic chemist.

\section{Acknowledgments}

We thank the Alexander von Humboldt Foundation for funding, provided within the framework of the Sofja Kovalevskaja Award endowed by the German Federal Ministry of Education and Research. We thank Prof. John C. Walton for helpful discussions on the interpretation of EPR spectra. We thank Regina Hoheisel for assistance and training in spectroelectrochemical measurements. We thank Prof. Patrick Nuernberger and Dr. Roger-Jan Kutta for insightful discussions on the photophysics of excited states. We thank Prof. Burkhard König for providing infrastructural support in setting up our laboratories. Computational work was supported by The Ministry of Education, Youth and Sports from the Large Infrastructures for Research, Experimental Development and Innovations Project “e-Infrastructure CZ - LM2018140”. This manuscript is dedicated to the memory of Dr. Matthew P. John who first suggested the use of TPA $\cdot{ }^{+} \mathrm{s}$ as oxidizing photocatalysts.

\section{Author Contributions}

†J.Ž., M.D. and P.H. contributed equally to this work.

S.W. performed the optimization study, conducted all photoelectrochemical reactions, synthesized $\mathrm{TPA}^{+}{ }^{+}$s and measured spectroelectrochemistry and UV-vis spectra of compounds. S.W., J.B. and J.Ž. designed TPAs while J.Ž. synthesized second generation TPAs (with support from M.D.) and performed XRD on TCBPA. While M.D. synthesized some starting materials. Under the guidance of J.R., P.H. measured and analyzed all EPR spectra of TPA. ${ }^{+}$s and precomplexes. V.B. and J.B. shared the DFT calculations of precomplexes, spin densities and TD-DFT calculations. D.J.S. performed XRD studies on TPA ${ }^{+}$s. A.K. measured TAS of TPA ${ }^{+}$s. E.T. measured fluorescence, EEM spectra and TCSPC of TPA. ${ }^{+}$s. J.H. and E.T. analyzed and interpreted TAS and luminescence data. J.B. and S.W. together wrote the manuscript and analyzed all other spectroscopic data. J.B. conceived and guided the study, designed photoelectrochemical cells, conducted all CV measurements, guided the overall project, facilitated collaborations. All authors checked the manuscript. 


\section{References:}

1. K. D. Moeller, Synthetic Applications of Anodic Electrochemistry. Tetrahedron 56, 9527-9554 (2000).

2. J.-I. Yoshida, K. Kataoka, R. Horcajada, A. Nagaki, Modern Strategies in Electroorganic Synthesis. Chem. Rev. 7, 2265-2299 (2008).

3. B. A. Frontana-Uribe, R. D. Little, J. G. Ibanez, A. Palma, R. Vasquez-Medrano, Organic electrosynthesis: a promising green methodology in organic chemistry. Green Chem. 12, 2099-2119 (2010).

4. M. Yan, Y. Kawamata, P. S. Baran, Synthetic Organic Electrochemical Methods Since 2000: On the Verge of a Re-naissance. Chem Rev. 117, 13230-13319 (2017).

5. A. Weibe, T. Geishoff, S. Möhle, E. Rodrigo, M. Zirbes, S. Waldvogel, Electrifying Organic Synthesis. Angew. Chem. Int. Ed. 57, 5594-5619 (2018).

6. K. Zeitler, Photoredox Catalysis with Visible Light. Angew. Chem. Int. Ed. 48, 9785-9789 (2009).

7. J. M. R. Narayanam, C. R. J. Stephenson, Visible light photoredox catalysis: applications in organic synthesis. Chem. Soc. Rev. 40, 102-113 (2011).

8. C. Prier, D. Rankic, D. W. C. MacMillan, Visible Light Photoredox Catalysis with Transition Metal Complexes: Applications in Organic Synthesis. Chem. Rev. 113, 5322-5363 (2013)

9. S. Fukuzumi, K. Ohkubo, Selective photocatalytic reactions with organic photocatalysts. Chem. Sci. 4, 561-574 (2013).

10. N. A. Romero, D. A. Nicewicz, Organic Photoredox Catalysis. Chem. Rev. 116, 10075-10166 (2016).

11. K. L. Skubi, T. R. Blum, T. P. Yoon, Dual Catalysis Strategies in Photochemical Systems. Chem. Rev. 116, 10035-10074 (2016).

12. J. K. Matsui, S. B. Lang, D. R. Heitz, G. A. Molander, Photoredox-Mediated Routes to Radicals: The Value of Catalytic Radical Generation in Synthetic Methods Development. ACS Catal. 7, 2563-2575 (2017).

13. I. Ghosh, T. Ghosh, J. I. Bardagi, B. König, Reduction of aryl halides by consecutive visible light-induced electron transfer processes. Science 346, 725-728 (2014).

14. L. Marzo, I. Ghosh, F. Esteban, B. König, Metal-Free Photocatalyzed Cross Coupling of Bromoheteroarenes with Pyrroles. ACS Catal. 6, 6780-6784 (2016). 
15. I. A. MacKenzie, L. Wang, N. P. R. Onuska, O. F. Williams, K. Begam, B. D. Duneitz, A. M. Moran, D. A. Nicewicz, Discovery and characterization of an acridine radical photoreductant. Nature 580, 76-80 (2020).

16. J. He, J. Li, Q. Han, C. Si, G. Niu, M. Li, J. Wang, J. Niu, Photoactive Metal-Organic Framework for the Reduction of Aryl Halides by the Synergistic Effect of Consecutive Photoinduced Electron-Transfer and Hydrogen-Atom-Transfer Processes. ACS Appl. Mater. Interfaces 12, 2199-2206 (2020).

17. J. P. Cole, D.-F. Chen, M. Kudisch, R. M. Pearson, C.-H. Lim, G. M. Miyake, Organocatalyzed Birch Reduction Driven by Visible Light. J. Am. Chem. Soc. 142, 13573-13581 (2020).

18. M. Majek, U. Faltermeier, B. Dick, R. Pérez-Ruiz, A. J. von Wangelin, Application of Visible-to-UV Photon Upconversion to Photoredox Catalysis: The Activation of Aryl Bromides. Chem.-Eur. J. 21, 15496-15501 (2015).

19. C. Kerzig, O. S. Wenger, Reactivity control of a photocatalytic system by changing the light intensity. Chem. Sci. 10, 11023-11029 (2019).

20. B. D. Ravetz, A. B. Pun, E. M. Churchill, D. N. Congreve, T. Rovis, L. M. Campos, Photoredox catalysis using infrared light via triplet fusion upconversion. Nature 565, 343-346 (2019).

21. M. Ghosh, V. S. Shinde, M. Rueping, A review of asymmetric synthetic organic electrochemistry and electrocatalysis: concepts, applications, recent developments and future directions. Beilstein J. Org. Chem. 15, 2710-2746 (2019).

22. Q. Lin, L. Li, S. Luo, Asymmetric Electrochemical Catalysis. Chem.-Eur. J. 25, 10033-10044 (2019).

23. C. Schotten, T. P. Nicholls, R. A. Bourne, N. Kapur, B. N. Nguyen, C. E. Willans, Making electrochemistry easily accessible to the synthetic chemist. Green. Chem. 22, 3358-3375 (2020).

24. T. Fuchigami, M. Atobe, S. Inagi, Fundamentals and Applications of Organic Electrochemistry: Synthesis, Materials, Devices, $1^{\text {st }}$ Ed., Wiley-VCH, Weinheim, pp. 217 (2015).

25. N. Elgrishi, K. J. Rountree, B. D. McCarthy, E. S. Rountree, T. T. Eisenhart, J. L. Dempsey, A Practical Beginner's Guide to Cyclic Voltammetry. J. Chem. Educ. 95, 197-206 (2018).

26. C. Costentin, J.-M. Savéant, Concepts and tools for mechanism and selectivity analysis in synthetic organic electrochemistry. PNAS 116, 11147-11152 (2019).

27. A. M. Couper, D. Pletcher, F. C. Walsh, Electrode Materials for Electrosynthesis. Chem. Rev. 90, 857-865 (1990). 
28. D. M. Heard, A. J. J. Lennox, Electrode Materials in Modern Organic Electrochemistry. Angew. Chem. Int. Ed. 59, 18866-18884 (2020).

29. J. P. Barham, B. König, Synthetic Photoelectrochemistry. Angew. Chem. Int. Ed. 59, 11732-11747 (2020).

30. R. H. Verschueren, W. M. De Borggraeve, Electrochemistry and Photoredox Catalysis: A Comparative Evaluation in Organic Synthesis. Molecules 24, 2122 (2019).

31. J. Liu, L. Lu, D. Wood, S. Lin, New Redox Strategies in Organic Synthesis by Means of Electrochemistry and Photochemistry. ACS Cent. Sci. 6, 1317-1340 (2020).

32. L. Capaldo, L. L. Quadri, D. Ravelli, Merging Photocatalysis with Electrochemistry: The Dawn of a new Alliance in Organic Synthesis. Angew. Chem. Int. Ed. 131, 17670-17672 (2019).

33. Y. Yu, P. Guo, J.-S. Zhong, Y. Yuan, K.-Y. Ye, Merging photochemistry with electrochemistry in organic synthesis. Org. Chem. Front. 7, 131-135 (2020).

34. H. Tateno, Y. Miseki, K. Sayama, Photoelectrochemical dimethoxylation of furan via a bromide redox mediator using a $\mathrm{BiVO}_{4} / \mathrm{WO}_{3}$ photoanode. Chem. Commun. 53, 4378-4381 (2017).

35. T. Li, T. Kasahara, J. He, K. E. Dettelbach, G. M. Sammis, Photoelectrochemical oxidation of organic substrates in organic media. Nat. Commun. 8, 390 (2020).

36. H. Tateno, Y. Iguchi, Y. Miseki, K. Sayama, Photo-Electrochemical C-H Bond Activation of Cyclohexane Using a $\mathrm{WO}_{3}$ Photoanode and Visible Light. Angew. Chem. Int. Ed. 57, 11238-11241 (2018).

37. L. Zhang, L. Liardet, J. Luo, D. Ren, M. Grätzel, X. Hu, Photoelectrocatalytic Arene C-H Amination. Nat. Catal. 2, 366-373 (2019).

38. R. Scheffold, R. Orlinski, Synthesis and reactions of porphine-type metal complexes. 15. Carbon-carbon bond formation by light assisted $\mathrm{B}_{12}$-catalysis. Nucleophilic acylation of Michael olefins. J. Am. Chem. Soc. 105, 7200-7202 (1983).

39. F. Wang, S. Stahl, Merging Photochemistry with Electrochemistry: Functional Group Tolerant Electrochemical Amination of C(sp $\left.{ }^{3}\right)-H$ Bonds. Angew. Chem. Int. Ed. 58, 6385-6390 (2019).

40. J.-C. Moutet, G. Reverdy, Photochemistry of cation radicals in solution: photoinduced oxidiation by the phenothiazine cation radical. Tetrahedron Lett. 20, 2389-2393 (1979). 
41. J.-C. Moutet, G. Reverdy, Photochemistry of cation radicals in solution: Photoinduced Electron-transfer Reactions between Alcohols and the N,N,N',N'-Tetraphenyl-p-phenylenediamine Cation Radical. J. Chem. Soc. Chem. Commun. 654-655 (1982).

42. S. S. Shukla, J. F. Rusling, Photoelectrocatalytic reduction of 4-chlorobiphenyl using anion radicals and visible light. J. Phys. Chem. 89, 3352-3358 (1985).

43. B. R. Eggins, P. K. J. Robertson, Photoelectrochemistry using quinone radical anions. J. Chem. Soc. Faraday Trans. 90, 2249-2256 (1994).

44. H. Yan, Z.-W. Hou, H.-C. Xu, Photoelectrochemical C-H Alkylation of Heteroarenes with Organotrifluoroborates. Angew. Chem. Int. Ed. 58, 4592-4595 (2019).

45. H. Huang, Z. M. Strater, M. Rauch, J. Shee, T. J. Sisto, C. Nickolls, T. H. Lambert, Electrophotocatalysis with a Trisaminocyclopropenium Radical Dication. Angew. Chem. Int. Ed. 58, 13318-13322 (2019).

46. H. Huang, T. H. Lambert, Electrophotocatalytic $\mathrm{S}_{\mathrm{N}} \mathrm{Ar}$ Reactions of Unactivated Aryl Fluorides at Ambient Temperature and Without Base. Angew. Chem. Int. Ed. 59, 658-662 (2020).

47. W. Zhang, K. L. Carpenter, S. Lin, Electrochemistry Broadens the Scope of Flavin Photocatalysis: Photoelectrocatalytic Oxidation of Unactivated Alcohols. Angew. Chem. Int. Ed. 59, 409-417 (2020).

48. H. Kim, H. Kim, T. H. Lambert, S. Lin, Reductive Electrophotocatalysis: Merging Electricity and Light to Achieve Extreme Reduction Potentials. J. Am. Chem. Soc. 142, 2087-2092 (2020).

49. N. G. W. Cowper, C. P. Chernowsky, O. P. Williams, Z. K. Wickens, Potent Reductants via Electron-Primed Photoredox Catalysis: Unlocking Aryl Chlorides for Radical Coupling. J. Am. Chem. Soc. 142, 2093-2099 (2020).

50. X.-L. Lai, X.-M. Shu, J. Song, H.-C. Xu, Electrophotocatalytic Decarboxylative C-H Functionalization of Heteroarenes. Angew. Chem. Int. Ed. 59, 10626-10632 (2020).

51. Y. Qiu, A. Scheremetjew, L. H. Finger, L. Ackermann, Electrophotocatalytic Undirected C-H Trifluoromethylations of (Het)Arenes. Chem.-Eur. J. 26, 3241-3246 (2020).

52. R. I. Walter, Triarylaminium Salt Free Radicals. J. Am. Chem. Soc. 77, 5999-6002 (1955).

53. Z. Ning, N. Tian, Triarylamine: a promising core unit for efficient photovoltaic materials. Chem. Comm. 5483-5495 (2009).

54. P. Cias, C. Slugovc, G. Gescheidt, Hole Transport in Triphenylamine Based OLED Devices: From Theoretical Modeling to Properties Prediction. J. Phys. Chem. A 115, 14519-14525 (2011). 
55. E. Steckhan, Indirect Electroorganic Syntheses-A Modern Chapter of Organic Electrochemistry. Angew. Chem. Int. Ed. 25, 683-701 (1986).

56. R. Francke, R. D. Little, Redox catalysis in organic electrosynthesis: basic principles and recent developments. Chem. Soc. Rev. 43, 2492-2521 (2014).

57. T. Fuchigami, M. Tetsu, T. Tajima, H. Ishii, Indirect Anodic Monofluorodesulfurization of $\beta$-Phenylsulfenyl $\beta$-lactams Using a Triarylamine Mediator. Synlett 8, 1269-1271 (2001).

58. X. Wu, A. P. Davis, A. J. Fry, Electrocatalytic Oxidative Cleavage of Electron-Deficient Substituted Stilbenes in Acetonitrile-Water Employing a New High Oxidation Potential Electrocatalyst. An Electrochemical Equivalent of Ozonolysis. Org. Lett. 9, 5633-5636 (2007).

59. C.-Y. Cai, H.-C. Xu, Dehydrogenative reagent-free annulation of alkenes with diols for the synthesis of saturated O-heterocycles. Nat. Commun. 9, 3551 (2018).

60. R. A. Pabon, D. J. Bellville, N. L. Bauld, Cation Radical Diels-Alder Reactions of Electron-Rich Dienophiles. J. Am. Chem. Soc. 105, 5158-5159 (1983).

61. D. W. Reynolds, K. T. Lorenz, H. S. Chiou, D. J. Bellville, R. A. Pabon, N. L. Bauld, Mechanistic diagnosis of aminium salt initiated Diels-Alder cycloadditions in the diene/diene format. J. Am. Chem. Soc. 109, 4960-4968 (1987).

62. P. S. Engel, A. K. M. M. Hoque, J. N. Scholz, H. J. Shine, K. H. Whitmire, The Reaction of 2,3-Diazabicyclo[2.2.2] oct-2-ene with Stable Cation Radical Salts. J. Am. Chem. Soc. 110, 7880-7882 (1988).

63. L. Eberson, B. Olofsson, The Reaction between Tris(4-bromophenyl)aminium Ion and Acetate Ion is an Electrophilic Reaction! Acta Chem. Scand. 43, 698-701 (1989).

64. F. Ciminale, L. Lopez, A. Nacci, L. D’Accolti, F. Vitale, Aminium Hexachloroantimonate Salts as Latent Sources of Antimony Pentachloride in Pinacolic Rearrangement of Vicinal Diols. Eur. J. Org. Chem. 1597-1603 (2005).

65. J. P. Barham, M. P. John, J. A. Murphy, Contra-thermodynamic Hydrogen Atom Transfer in the Selective $\mathrm{N}-\mathrm{CH}_{3}$ Functionalization of Trialkylamines. J. Am. Chem. Soc. 138, 15482-15487 (2016).

66. N. A. Romero, K. A. Margrey, E. N. Tay, D. A. Nicewicz, Site-selective arene C-H amination via photoredox catalysis. Science 349, 1326-1330 (2015). 
67. S. Das, P. Natarajan, B. König, Teaching Old Compounds New Tricks: DDQ-Photocatalyzed C-H Amination of Arenes with Carbamates, Urea and N-heterocycles. Chem.-Eur. J. 23, 18161-18165 (2017).

68. S. Fukuzumi, J. Yuasa, N. Satoh, T. Suenobu, Scandium Ion-Promoted Photoinduced Electron Transfer from Electron Donors to Acridine and Pyrene. Essential Role of Scandium Ion in Photocatalytic Oxygenation of Hexamethylbenzene. J. Am. Chem. Soc. 126, 7585-7594 (2004).

69. V. A. Pistritto, M. E. Schutzbach-Horton, D. A. Nicewicz, Nucleophilic Aromatic Substitution of Unactivated Fluoroarenes Enabled by Organic Photoredox Catalysis. J. Am. Chem. Soc. 142, 17187-17194 (2020).

70. M. Fujitsuka, T. Majima, Reaction dynamics of excited radical ions revealed by femtosecond laser flash photolysis. J. Photochem. Photobiol. C 35, 25-37 (2018).

71. A. P. Demchenko, V. I. Tomin, P.-T. Chou, Breaking the Kasha Rule for More Efficient Photochemistry. Chem. Rev. 117, 13353-13381 (2017).

72. D. Gosztola, M. P. Niemczyk, W. Svec, A. S. Lukas, M. R. Wasielewski, Excited Doublet States of Electrochemically Generated Aromatic Imide and Diimide Radical Anions. J. Phys. Chem. A 104, 6545-6551 (2000).

73. C. Lu, M. Fujitsuka, A. Sugimoto, T. Majima, Unprecedented Intramolecular Electron Transfer from Excited Perylenediimide Radical Anion. J. Phys. Chem. C 120, 12734-12741 (2016).

74. J. A. Christensen, B. T. Phelan, S. Chaudhuri, A. Acharya, V. S. Batista, M. R. Wasielewski, Phenothiazine Radical Cation Excited States as Super-oxidants for Energy-Demanding Reactions. J. Am. Chem. Soc. 140, 5290-5299 (2018).

75. J. Grilj, P. Buchgraber, E. Vauthey, Excited-State Dynamics of Wurster's Salts. J. Phys. Chem. A 116, 7516-7522 (2012).

76. J. Köhler, T. Quast, J. Buback, I. Fischer, B T.rixner, P. Nuernberger, B. Geiß, J. Mager, C. Lambert, Lanthanide ions as spectral converters for solar cells. Phys. Chem. Chem. Phys. 14, 11081-11089 (2012).

77. W. C. Neikam, G. M. Dimeler, M. M. Desmond, A Correlation of Electrochemical Oxidation Potential of Organic Compounds with Photoionization Potential. J. Electrochem. Soc. 111, 1190-1192 (1964).

78. L. Fajarí, R. Papoular, M. Reig, E. Brillas, J. L. Jorda, O. Vallcorba, J. Rius, D. Velasco, L. Juliá, Charge Transfer States in Stable Neutral and Oxidized Radical Adducts from Carbazole Derivatives. J. Org. Chem. 79, 1771-1777 (2014). 
79. S. Amthor, B. Noller, C. Lambert, UV/Vis/NIR spectral properties of triarylamines and their corresponding radical cations. Chem. Phys. 316, 141-152 (2005).

80. Y. Su, X. Wang, L. Wang, Z. Zhang, X. Wang, Y. Song, P. P. Power, Thermally controlling the singlet-triplet energy gap of a diradical in the solid state. Chem. Sci. 7, 6514-6518 (2016).

81. C. A. Hunter, J. K. M. Sanders, The nature of $\pi-\pi$ interactions. J. Am. Chem. Soc. 112, 5525-5534 (1990).

82. C. R. Martinez, B. L. Iverson, Rethinking the term 'pi-stacking'. Chem. Sci. 3, 2191-2201 (2012).

83. L. M. da Costa, S. R. Stoyanov, S. Gusarov, X. Tan, M. R. Gray, J. M. Stryker, R. Tykwinski, J. W. de M. Carneiro, P. R. Seidl, Density Functional Theory Investigation of the Contributions of $\pi-\pi$ stacking and Hydrogen-Bonding Interactions to the Aggregation of Model Asphaltene Compounds. Energy Fuels 26, 2727-2735 (2012).

84. A. Muraoka, M. Hayashi, Electronic structure of sumanene-type Buckycatcher by DFT calculations. Chem. Phys. Lett. 748, 137393 (2020).

85. D. E. Williams, Y. Xiao, Benzene, Naphthalene and Anthracene Dimers and their Relation to the Observed Crystal Structures. Acta Cryst. 49, 1 (1993).

86. M. O. Sinnokrot, C. D. Sherrill, Substituent Effects in $\pi-\pi$ Interactions: Sandwich and T-Shaped Configurations. J. Am. Chem. Soc. 126, 7690-7697 (2004).

87. M. Hajji, H. Mtiraoui, N. Amiri, M. Msaddek, T. Guerfel, Cystallographic and first-principles density functional theory study on the structure, noncovalent interactions, and chemical reactivity of 1,5-benzodiazepin-2-ones derivatives. Int. J. Quantum Chem. 119, e26000 (2019).

88. T. Gao, T. Li, W.Li, L. Li, C. Fang, H. Li, L. Hu, Y. Lu, Z.-M. Su, A machine learning correction for DFT non-covalent interactions based on the S22, S66 and X40 benchmark databases. J. Cheminform 8, 24 (2016).

89. K. Wang, J. Lv, J. Miao, Assessment of density functionals and force field methods on anion- $\pi$ interaction in heterocyclic calix complexes. Theor. Chem. Acc. 134, 5 (2015).

90. Z. Zara, J. Iqbal, K. Ayub, M. Irfan, A. Mahmood, R. A. Khera, B. Eliasson, A comparative study of DFT calculated and experimental UV/Visible spectra for thirty carboline and carbazole based compounds. J. Mol. Structure 1149, 282-298 (2017). 
91. B. C. Lin, C. P. Cheng, Z. P. M. Lao, Reorganization Energies in the Transports of Holes and Electrons in Organic Amines in Organic Electroluminescence Studies by Density Functional Theory. J. Phys. Chem. A 107, $5241-5251(2003)$.

92. R. L. Martin, Natural transition orbitals. J. Chem. Phys. 118, 4775-4777 (2003). 